\title{
Three Cases of Enduring Memory Impairment after Bilateral Damage Limited to the Hippocampal Formation
}

\author{
Nancy L. Rempel-Clower, ${ }^{3}$ Stuart M. Zola, ${ }^{1,2,3}$ Larry R. Squire, ${ }^{1,2,3}$ and David G. Amaral ${ }^{4}$ \\ 1 Veterans Affairs Medical Center, San Diego, California 92161, Departments of ${ }^{2} P$ sychiatry and ${ }^{3}$ Neurosciences, \\ University of California at San Diego, La Jolla, California 92093, and ${ }^{4}$ Department of Psychiatry and Center for \\ Neuroscience, University of California at Davis, Davis, California 95616
}

\begin{abstract}
Patient RB (Human amnesia and the medial temporal region: enduring memory impairment following a bilaterial lesion limited to field CA1 of the hippocampus, S. Zola-Morgan, L. R. Squire, and D. G. Amaral, 1986, J Neurosci 6:2950-2967) was the first reported case of human amnesia in which detailed neuropsychological analyses and detailed postmortem neuropathological analyses demonstrated that damage limited to the hippocampal formation was sufficient to produce anterograde memory impairment. Neuropsychological and postmortem neuropathological findings are described here for three additional amnesic patients with bilateral damage limited to the hippocampal formation. Findings from these patients, taken together with the findings from patient RB and other amnesic patients, make three important points about memory. (1) Bilateral damage limited primarily to the CA1 region of the hippocampal formation is sufficient to produce moderately severe
\end{abstract}

anterograde memory impairment. (2) Bilateral damage beyond the CA1 region, but still limited to the hippocampal formation, can produce more severe anterograde memory impairment. (3) Extensive, temporally graded retrograde amnesia covering 15 years or more can occur after damage limited to the hippocampal formation. Findings from studies with experimental animals are consistent with the findings from amnesic patients. The present results substantiate the idea that severity of memory impairment is dependent on locus and extent of damage within the hippocampal formation and that damage to the hippocampal formation can cause temporally graded retrograde amnesia.

Key words: hippocampal formation; CA1 region; human amnesia; anterograde memory impairment; retrograde memory impairment; temporally graded retrograde amnesia
The medial temporal lobe has been recognized as important for memory for nearly a century (von Bechterew, 1900; Grunthal, 1947; Glees and Griffith, 1952; Scoville and Milner, 1957). More recently, damage to the hippocampal formation (hippocampus proper, dentate gyrus, subicular complex, and entorhinal cortex) has been associated with memory impairment in case studies of amnesic patients (Victor et al., 1961; DeJong et al., 1968; Van Buren and Borke, 1972; Muramoto et al., 1979; Woods et al., 1982; Cummings et al., 1984; Duyckaerts et al., 1985; ZolaMorgan et al., 1986; Victor and Agamanolis, 1990; Warrington and Duchen, 1992). However, for most of these cases it is uncertain whether the lesions were limited to the hippocampal formation, and frequently, only anecdotal evidence of memory impairment rather than rigorous memory testing was available.

Patient RB (Zola-Morgan et al., 1986) was the first reported case of human amnesia in which detailed neuropsychological analyses and detailed postmortem neuropathological analyses demonstrated that damage limited to the hippocampal formation

\footnotetext{
Received March 21, 1996; revised May 30, 1996; accepted June 3, 1996.

This work was supported by the Human Frontiers Science Program, the Medical Research Service of the Department of Veterans Affairs, National Institute of Mental Health Grant MH24600, the McKnight Foundation, the Office of Naval Research, National Institutes of Health Grant NS 16980, and a McDonnell-Pew predoctoral fellowship in cognitive neurosciences (N.R.-C.). We thank Dr. Mark Kritchevsky, Dr. Eliezer Masliah, Cecelia LeClair, Amy Lockwood, and Scott Hanson for their contributions, and we thank the patients and their families for their cooperation and encouragement.

Correspondence should be addressed to Stuart M. Zola, Department of Psychiatry 0603, University of California at San Diego School of Medicine, La Jolla, CA 92093.

Dr. Rempel-Clower's present address: Department of Health Sciences, Boston University, Boston, MA 02215.

Copyright (C) 1996 Society for Neuroscience $0270-6474 / 96 / 165233-23 \$ 05.00 / 0$
}

was sufficient to produce anterograde memory impairment. Specifically, RB had bilateral damage limited to the CA1 field of the hippocampus, and he had moderately severe anterograde amnesia. Anterograde amnesia was subsequently reported in another case with well documented, postmortem histological analysis in which damage was limited to the hippocampal formation (Victor and Agamanolis, 1990).

Patient RB had little detectable retrograde amnesia (ZolaMorgan et al., 1986); except for perhaps the year or 2 immediately preceding his ischemic event, he had good memory of events that had occurred before the onset of amnesia. Other amnesic patients with confirmed medial temporal lobe damage also have been reported, based on clinical interviews and family reports, to have limited, temporally graded retrograde amnesia affecting a few years or less before the onset of amnesia (Victor et al., 1961: 2 years; Penfield and Milner, 1958: patient A, a glove-cutter, 4 years; patient B, a civil engineer, less than 3 months). By contrast, formal testing of amnesic patients with radiologically confirmed damage to the hippocampal formation has documented temporally graded retrograde amnesia covering at least 15 years (Beatty et al., 1987a; Salmon et al., 1988; Squire et al., 1989). In addition, formal testing of patient HM, who became severely amnesic at the age of 27 after bilateral resection of the medial temporal lobe, indicated retrograde amnesia covering up to 11 years (Corkin, 1984).

These results from the available studies of amnesic patients with damage to the hippocampal formation raise a number of questions. First, patient RB exhibited moderately severe anterograde amnesia in association with a circumscribed CA1 hippocam- 
pal lesion. Is this a typical and repeatable finding after global ischemia? Does damage limited to the CA1 region ordinarily result in moderately severe anterograde memory impairment? Second, does damage beyond the CA1 region, but still limited to the hippocampal formation, produce more severe anterograde memory impairment? Third, RB's CA1 lesion resulted in quite limited retrograde amnesia. What damage is required to produce the more extensive, temporally graded retrograde amnesia that can be documented in formal testing (Beatty et al., 1987a; Salmon et al., 1988; Squire et al., 1989)?

Neuropsychological and postmortem neuropathological findings are described here for three amnesic patients with bilateral medial temporal lobe damage. They varied in the severity of their anterograde amnesia and in the extent of their retrograde amnesia. The patients survived for more than 6 years after the onset of amnesia, during which time they received extensive neuropsychological testing of memory and other cognitive functions.

\section{MATERIALS AND METHODS}

Three amnesic patients (GD, LM, and WH) were studied from the onset of amnesia until their deaths 6 to 9.5 years later. Their case histories are described below.

\section{Patient $G D$}

Case history. Patient GD was a Caucasian male born in 1940. He joined the Navy after graduating from high school and served for 16 years, ultimately as a navigator. After his service in the Navy, he owned a wrecking business. In 1976, GD was diagnosed with hypertension thought to be secondary to nephrosclerosis. In August 1981, he was diagnosed with chronic renal failure. A biopsy showed focal crescentic glomerulonephritis, and hemodialysis was begun in February 1982. He received hemodialysis three times a week for the remainder of his life.

In May 1983, GD was hospitalized for elective parathyroidectomy to relieve severe itching attributable to hyperparathyroidism. (His parathyroid hormone level was $78,000 \mathrm{pg} / \mathrm{ml}$ compared with normal levels of $<150 \mathrm{pg} / \mathrm{ml}$.) The $5 \mathrm{hr}$ procedure consisted of a total parathyroidectomy with autotransplantation of some parathyroid tissue to the right forearm. He also underwent left thyroid lobectomy because of loss of blood to the left lobe of the thyroid during removal of the parathyroids. Two and a half hours into surgery he experienced cardiac arrhythmia (a junctional rhythm), and his heart rate dropped to 45 beats/min. For a period of 15 $\mathrm{min}$ at that time, his blood pressure was $100-110 / 50-60 \mathrm{mmHg}$. His recorded blood pressure sometimes had also been low immediately after dialysis treatment during the 7 months before surgery (80-150/50-100 $\mathrm{mmHg}$ ).

After this ischemic episode, GD was noted in the hospital records to be agitated, disoriented, and very forgetful of events from the preceding 5 min. He was discharged $5 \mathrm{~d}$ after the surgery and was still unable to remember what he had recently said or done. Beginning 2 months after surgery and continuing intermittently for 9.5 years, he was given a variety of neuropsychological tests (described below).

GD gave no evidence of intellectual or cognitive deficit other than memory impairment. He exhibited little interest in testing, however, and this complicated the interpretation of some of his memory test scores (see below). His memory impairment remained stable for the next 9.5 years until his death. In December 1992, GD died of congestive heart failure secondary to uremic pericarditis and end-stage renal disease. He was 52 years old.

Acquisition and preparation of tissue. Approximately $3 \mathrm{hr}$ after death, GD's brain was removed and placed in $4 \%$ paraformaldehyde with $0.02 \%$ picric acid. The carotid arteries were cannulated, and the brain was perfused with the paraformaldehyde solution for $1 \mathrm{hr}$ and then for 3 more hours with fresh $4 \%$ paraformaldehyde in $0.1 \mathrm{~m}$ phosphate buffer.

Photographs of the whole brain surfaces were taken, and then the brain was cut into $\sim 1$-cm-thick coronal blocks and placed in $4 \%$ paraformaldehyde in $0.1 \mathrm{M}$ phosphate buffer for $48 \mathrm{hr}$. The blocks were then stored in cold $10 \%$ formalin in $0.1 \mathrm{M}$ phosphate buffer for approximately 9 months. Then, the blocks were placed in a cryoprotectant solution of $20 \%$ glycerol and $2 \%$ dimethyl sulfoxide in $0.1 \mathrm{~m}$ phosphate buffer for $2 \mathrm{~d}$ before freezing. Whole coronal blocks were frozen between glass slides by placing them in $-70^{\circ} \mathrm{C}$ isopentane for $45 \mathrm{~min}$ and stored at $-70^{\circ} \mathrm{C}$ until they were cut.

\section{Patient LM}

Case history. Patient LM has been described previously (as patient MRL in Beatty et al., 1987a,b). He was a Caucasian male born in 1930. LM enlisted in the Marine Corps after graduating from high school and served for 20 years. For the next 17 years, he worked as a surveyor's assistant and during that time completed 3 years of college.

LM had a history of alcohol abuse and was treated in the Alcoholism Treatment Program at the San Diego Veterans Affairs Medical Center (VAMC) in 1980. During the 6 months before treatment, he estimated his average daily intake of alcohol at 16 drinks. He denied using other psychoactive drugs.

LM began to have seizures while on military duty, often associated with alcohol withdrawal. According to his former wife, a nurse at the San Diego VAMC, he experienced generalized tonic clonic seizures in 1964, $1967,1978,1980$, and 1984 . The seizures were usually preceded by visual images of flashing lights sometimes followed by other images. His former wife reported that he fully recovered from the first four seizures, and that his intellectual faculties seemed entirely normal before the 1984 seizures (see below). Periodic neurological evaluations after seizures from 1964 to 1984 were normal. LM began taking anticonvulsants regularly after the 1984 seizures and did not have further tonic clonic seizures. However, according to his former wife, he did have partial seizures that ranged in frequency from once in 2 weeks to sometimes as often as three to four times a day. During these episodes, he would be unresponsive to visual or auditory stimuli and moved his lips in a chewing motion.

Although LM's drinking was reportedly minimal after 1980, his former wife reported that he had six to seven drinks of hard liquor and some beer $\sim 2 \mathrm{~d}$ before suffering a series of generalized tonic clonic seizures on September 27, 1984. While LM was riding in an automobile with coworkers, he complained of feeling dizzy and then had at least three tonic clonic seizures. He was brought to the emergency room and was comatose postictally for $\sim 2 \mathrm{hr}$. There was evidence of respiratory acidosis $(\mathrm{pH}, 6.8$; $\left.\mathrm{pCO}_{2}, 64\right)$, and an electroencephalogram (EEG) revealed diffuse sharp waves and delta activity. LM required respiratory assistance for at least 18 hr. On September 29, he was alert but disoriented to time and place. A neurological exam showed that his pupillary responses were normal and that he had normal reflexes and strength in all extremities, and an appropriate response to pain. One week later, an EEG showed mild-tomoderate generalized nonspecific abnormalities, i.e., slowing, but no focal abnormalities or epileptiform discharges were apparent. A CT brain scan, without contrast, was normal.

In his initial interview with a neuropsychologist (Dr. Nelson Butters, San Diego VAMC), he was oriented to person but not to place. He was unsure whether he was married at present (he was living with his former wife) and did not know which of his children were daughters or stepdaughters. During this initial interview, he even forgot the questions he was attempting to answer. He gave no evidence of intellectual or cognitive deficit other than memory impairment. His memory impairment remained stable for the next 6 years.

In July 1990, LM was diagnosed with a small cell carcinoma of the lung. Neuropsychological tests administered in August 1990 detected no changes in memory or other cognitive functions, and he remained alert and lucid until a few days before his death. LM died of respiratory failure October 27, 1990, at the age of 60.

Acquisition and preparation of tissue. LM's brain was removed at autopsy $\sim 1.5 \mathrm{hr}$ after death and placed in cold $0.9 \%$ saline. The carotid arteries were cannulated and the brain was perfused with $0.9 \%$ saline for 30 min, then perfused with $4 \%$ paraformaldehyde with $0.02 \%$ picric acid for $30 \mathrm{~min}$. This was replaced with fresh $4 \%$ paraformaldehyde after 30 $\mathrm{min}$, and the perfusion was continued for another $30 \mathrm{~min}$.

Photographs of the whole brain surfaces were taken, and the brain was cut into coronal blocks $\sim 1 \mathrm{~cm}$ thick and placed in cold $4 \%$ paraformaldehyde with $10 \%$ glycerol and $2 \%$ dimethylsulfoxide for $2 \mathrm{hr}$. The brain was cryoprotected in $20 \%$ glycerol and $2 \%$ dimethylsulfoxide in $0.1 \mathrm{M}$ phosphate buffer for $4 \mathrm{~d}$, and frozen as described for patient GD.

After sections from the anterior blocks (anterior 30\% of the brain) were mounted and stained with thionin, problems were noted in the fixation. Specifically, numerous small areas were stained more poorly with thionin than the surrounding tissue. This problem did not appear to be related to the staining procedure because adjacent sections showed the same pattern of blotchy staining. The remaining blocks were therefore thawed and placed in $4 \%$ paraformaldehyde, $20 \%$ glycerol, and $2 \%$ 
dimethylsulfoxide in $0.1 \mathrm{M}$ phosphate buffer to fix for an additional 3 months. The blocks were then refrozen until they were sectioned. No problems with staining were noted after the additional fixation.

\section{Patient $W H$}

Case history. Patient WH has been described previously (Salmon et al., 1988; Kritchevsky and Squire, 1993). He was a Caucasian male born in 1923, who obtained 17 years of education and worked as a systems engineer. Before his amnesic episode in 1986, WH had a 10 year history of mild, successfully treated hypertension. He was a former alcoholic and had stopped drinking 18 years before his episode. He had also been a heavy smoker for more than 20 years but had quit smoking 5-6 years before his episode. In February 1985, his wife found him unconscious in their home. She described a rhythmic jerking motion of his right arm. After hospitalization, he was noted to be confused and amnesic regarding the events of the previous night's episode of unconsciousness. He was treated for myocardial infarction as well as for atrial and ventricular arrhythmias. Brain CT without contrast was normal. He apparently made a full recovery with no evidence of cognitive impairment, and he was promoted at his job the next year.

WH developed severe memory impairment during March 25-30, 1986, at the age of 63. His wife reported that on the evening of March 25, 1986, he appeared tired and withdrawn. Although he seemed strained and looked ashen, he nevertheless went to work the next day. That evening he admitted to his wife that he was having memory problems. He could not recollect the appearance of his desk at work or his employer's face. He remained at home for the next $3 \mathrm{~d}$ during which time he was quiet and passive, often repeated himself, and forgot what he was doing after brief distractions. His wife reported that his memory problems became more severe on March 30. After admission to the hospital, a neurological examination on April 2 revealed him to be alert and normally attentive. He was uncertain of the month and day (believing it was February on two of three occasions), was uncertain about who was President, and did not know who was the governor of his state or the current mayor of his city. He recalled his address and home telephone number, but could not recall his work number. He was able to do simple tests of calculation, but could not recall the names of four objects that had been given $1 \mathrm{~min}$ before. His speech was clear and lucid, and his remote memory was reported as intact. Although the cause of his memory impairment was not determined with certainty, it has been suggested that it was attributable to cerebral ischemia, i.e., a period of relative hypotension, the effects of which could have been exacerbated by preexisting subclinical damage to the medial temporal lobe (Kritchevsky and Squire, 1993).

After his episode in 1986, WH was admitted to the hospital several times for episodes of shortness of breath and cardiac insufficiency. In addition, an ataxia developed in 1987, which was reported to have been resolved in 1989. In February 1988, he was admitted to the hospital after an episode of shortness of breath and chest pain. During this hospitalization, he suffered one tonic clonic seizure associated with his compromised pulmonary status and secondary to treatment with theophylline. On June 5, 1992, he was admitted to the hospital after three separate episodes of anomic aphasia and was diagnosed as having sustained three transient ischemic attacks.

Except during the transient episodes just noted, WH never exhibited signs of intellectual or cognitive deficits other than memory impairment. After the episode in 1986, his memory impairment remained stable for 7.5 years, during which time he was given a variety of neuropsychological tests (described below). He died in December 1993 from end-stage emphysema at the age of 71 .

Acquisition and preparation of tissue. WH's brain was removed at autopsy $\sim 2.5 \mathrm{hr}$ after death and placed in cold $4 \%$ paraformaldehyde with $0.02 \%$ picric acid. The carotid arteries were cannulated, and the brain was perfused with fresh $4 \%$ paraformaldehyde in $0.1 \mathrm{~m}$ phosphate buffer for $3 \mathrm{hr}$. The brain was then placed in fresh $4 \%$ paraformaldehyde in $0.1 \mathrm{M}$ phosphate buffer for $\sim 19 \mathrm{hr}$, at which time photographs of the whole brain surfaces were taken. The brain was then cut into coronal blocks $\sim 1 \mathrm{~cm}$ thick, and the blocks were stored in cold $4 \%$ paraformaldehyde in $0.1 \mathrm{M}$ phosphate buffer for $48 \mathrm{hr}$. The brain was then cryoprotected in $10 \%$ glycerol with $2 \%$ dimethylsulfoxide in $0.1 \mathrm{M}$ phosphate buffer for $2 \mathrm{~d}$, then in $20 \%$ glycerol with $2 \%$ dimethylsulfoxide in $0.1 \mathrm{M}$ phosphate buffer for $2 \mathrm{~d}$, and frozen as described for patient GD.

Processing of brain tissue. Beginning when the brains were frozen, all three were processed in the same way. Continuous $50 \mu \mathrm{m}$ sections were cut through each frozen block using a large freezing microtome designed specifically for cutting whole human brain tissue (Tetrander I). Every tenth section was mounted on gelatin-coated slides and stained with $0.25 \%$ thionin. The unmounted sections were stored in a cryoprotectant solution of $30 \%$ ethylene glycol and $25 \%$ glycerol in $0.1 \mathrm{M}$ phosphate buffer at $-70^{\circ} \mathrm{C}$.

Evaluation of brain tissue. Sections were analyzed with a Leitz Wild stereomicroscope. Thionin-stained sections through the brains of GD, $\mathrm{LM}$, and $\mathrm{WH}$ were examined together with comparable sections from two normal control brains. Each of the two control brains were obtained within $3.5 \mathrm{hr}$ of death, and they were processed using the procedures described for the patient brains. One control brain came from an 85-yearold male who died from pneumonia, and the other from a 54-year-old male who died from esophageal carcinoma. Adjacent sections of selected levels throughout the hippocampal formation of GD and LM were stained using a modified Heidenhain procedure (Hutchins and Weber, 1983). High-magnification photographs were taken with a $35 \mathrm{~mm}$ camera attached to a Leitz Dialux microscope. Low-magnification photographs were made with a Nikon Multiphot $4 \times 5$ macrophotography system.

\section{RESULTS}

Neuropsychological data from the patients will be described first, followed by the postmortem neuropathological findings. As mentioned above, all three patients were tested on multiple occasions beginning shortly after the onset of amnesia until their deaths. GD was tested for 9.5 years, LM for 6.0 years, and $\mathrm{WH}$ for 7.5 years. In the case of tests given on more than one occasion, scores presented here are from the latest administration of the test. No significant changes in memory or cognitive abilities were noted in any patient during the years they were studied.

\section{Neuropsychological findings}

Data for patients GD, LM, and WH will be presented together with comparable data for patient RB and two other groups of amnesic patients. (1) RB became amnesic in 1978 after an ischemic episode (Zola-Morgan et al., 1986). Comprehensive neuroanatomical examination after his death 5 years later revealed a bilateral lesion limited to the CA1 field of the hippocampus. (2) The medial temporal lobe (MTL) group includes three amnesic patients with radiologically confirmed or suspected damage to the medial temporal lobe. Patient AB became amnesic in 1976 after an anoxic episode during cardiac arrest. Patient $\mathrm{PH}$ had a 6 year history of occasional 1-2 min episodes (of possible epileptic origin) in association with gastric symptoms and transient memory impairment. In 1989, he suffered a series of episodes that resulted in marked and persisting memory impairment. Patient LJ became amnesic gradually between September 1988 and February 1989, without any known precipitating event. Her memory impairment has remained stable since then. Two of these patients ( $\mathrm{PH}$ and $\mathrm{LJ}$ ) participated in magnetic resonance imaging (MRI) studies that demonstrated reductions in the volume of the hippocampal region bilaterally (for PH, Polich and Squire, 1993; for LJ, unpublished observations). Patient AB was unable to participate in MRI studies because he wears a pacemaker, but he was presumed to have hippocampal damage based on his etiology. (3) Eight patients with alcoholic Korsakoff's syndrome (KOR group) were also tested. Six of these patients were reported previously in Squire and Shimamura (1986; NC, VF, BL, DM, PN, and JW), and two were reported in Knowlton and Squire (1994; RC and NF).

Table 1 shows the full-scale Wechsler Adult Intelligence ScaleRevised (WAIS-R) and Wechsler Memory Scale-Revised (WMS-R) for patients GD, LM, WH, RB, and the MTL and KOR groups. The Vocabulary and Information subscale scores of the WAIS-R are listed separately, as they are relatively resistant to impairment after focal brain injury (Goodglass and Kaplan, 1979). The patients also were given the original versions of both the Wechsler Adult Intelligence Scale (WAIS) and the Wechsler 
Table 1. Characteristics of amnesic patients

\begin{tabular}{|c|c|c|c|c|c|c|c|c|c|}
\hline \multirow[b]{2}{*}{ Patient/group } & \multirow[b]{2}{*}{ Age } & \multicolumn{3}{|l|}{ WAIS-R } & \multicolumn{5}{|l|}{ WMS-R } \\
\hline & & Full-scale & Vocabulary & Information & Attention & Verbal & Visual & General & Delay \\
\hline GD & 43 & 92 & 39 & 16 & 109 & 86 & 88 & 85 & 60 \\
\hline WH & 64 & 113 & 64 & 27 & 88 & 72 & 82 & 67 & $<50$ \\
\hline $\mathrm{RB}$ & 52 & 103 & 50 & 18 & - & - & - & - & - \\
\hline MTL (3) & $\begin{array}{l}59.0 \\
{[54-69]}\end{array}$ & $\begin{array}{l}105.7 \\
{[98-115]}\end{array}$ & $\begin{array}{l}56.0 \\
{[50-65]}\end{array}$ & $\begin{array}{l}22.6 \\
{[17-27]}\end{array}$ & $\begin{array}{l}103.0 \\
{[87-117]}\end{array}$ & $\begin{array}{l}70.6 \\
{[62-83]}\end{array}$ & $\begin{array}{l}71.7 \\
{[60-83]}\end{array}$ & $\begin{array}{l}64.3 \\
{[54-70]}\end{array}$ & $\begin{array}{l}52.3 \\
{[<50-57]}\end{array}$ \\
\hline
\end{tabular}

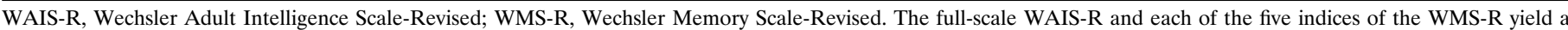

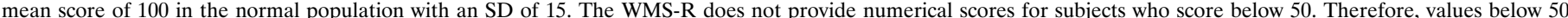

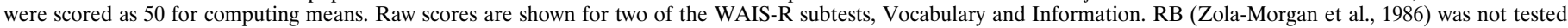

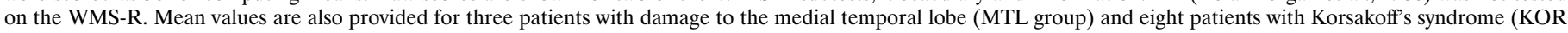
group). The ages are the age at the time of onset of amnesia. Brackets indicate ranges.

Memory Scale (WMS). A difference of more than 15 points between the WAIS and the WMS suggests a significant memory impairment. Patient RB had a difference score of 20 points (WAIS $=111$, WMS $=91)$. Patients GD and LM had difference scores of 28 and 18, respectively (GD: WAIS $=104$, WMS $=76$; LM: WAIS $=123$, WMS $=105$ ). Patient WH obtained a difference score of 31 in January 1987 and a difference score of 44 in July 1987 (WAIS = 120 and 127, respectively; WMS = 89 and 83, respectively).

\section{Anterograde memory}

Table 2 shows the scores for six measures of anterograde memory function. The mean scores for a group of eight control subjects are also included (Shimamura and Squire, 1986). The control subjects averaged 50.9 years of age (range, 44-54 years) and had mean WAIS-R subtest scores of 51.8 for Vocabulary (range, 38-65) and 21.9 for Information (range, 16-26). Patients GD, LM, and WH exhibited deficits in learning new material on tests of both recall (diagram recall, paired associate learning, word recall) and recognition (word recognition, face recognition), and on both verbal and nonverbal material. Figure 1 shows the copies and delayed reproductions of the Rey-Osterrieth figure for patients GD, LM, $\mathrm{WH}$, and one control subject. Although the amnesic patients could copy the figure accurately (copy scores: $\mathrm{GD}=32 ; \mathrm{LM}=33$; $\mathrm{WH}=30$; maximum possible: 36 ), they were unable to reproduce the figure from memory a short time later (see Table 2 for scores). WH performed worse than GD and LM.

WH's scores are lower than LM's scores on all six tests and lower than or equal to GD's scores on four of the six tests. WH also had lower scores than either GD or LM on the WMS-R (Table 1) and had the largest WAIS-WMS difference score. Thus, WH had more severe anterograde amnesia than GD or LM. No difference in severity of anterograde amnesia was apparent for GD and LM. However, GD's lower IQ (17 points below LM) raises the possibility that GD was in fact less amnesic than LM but performed poorly in part because of his general testing ability (see Retrograde memory, below). Finally, RB was given two of the same tests of anterograde memory as GD, LM, and WH: diagram recall test (score $=3$ ) and paired associates test (total score for 3 trials $=1$ ). RB's performance on these two tests and his WAISWMS difference score (20) suggest that the severity of RB's anterograde amnesia was similar to that of GD and LM and less severe than that of $\mathrm{WH}$.

\section{Retrograde memory}

Patients GD, LM, and WH also were tested for their memory of events that had occurred before the onset of amnesia (retrograde memory). Descriptions of the tests of retrograde memory and data for these three patients, as well as other amnesic patients, have been published previously (Beatty et al., 1987a; Salmon et

\begin{tabular}{|c|c|c|c|c|c|c|}
\hline Patient/group & Diagram recall & Paired associates & Word recall & Word recognition & 50 words & 50 faces \\
\hline GD & 7 & $2-1-2$ & 40 & 83 & 25 & 28 \\
\hline WH & 1 & $0-0-0$ & 40 & 84 & 29 & 24 \\
\hline $\mathrm{RB}$ & 3 & $0-0-1$ & - & - & - & - \\
\hline MTL (3) & 3.3 & $0.3-0.3-1.0$ & 33.3 & 86.5 & 33.6 & 32.0 \\
\hline & {$[11-28]$} & & [52-93] & [96-99] & {$[33-45]$} & [33-45] \\
\hline
\end{tabular}

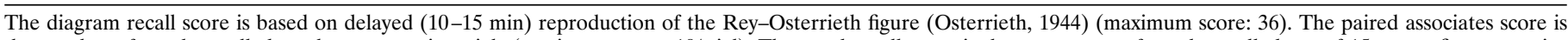

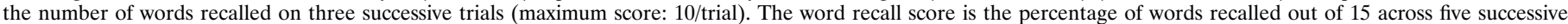

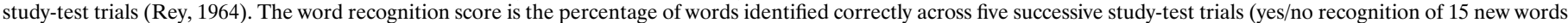

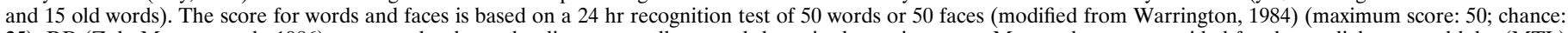

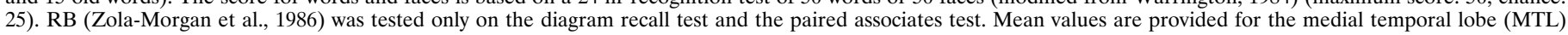
and Korsakoff's syndrome (KOR) groups. The mean scores for control subjects are from Squire and Shimamura (1986). Brackets indicate ranges. 

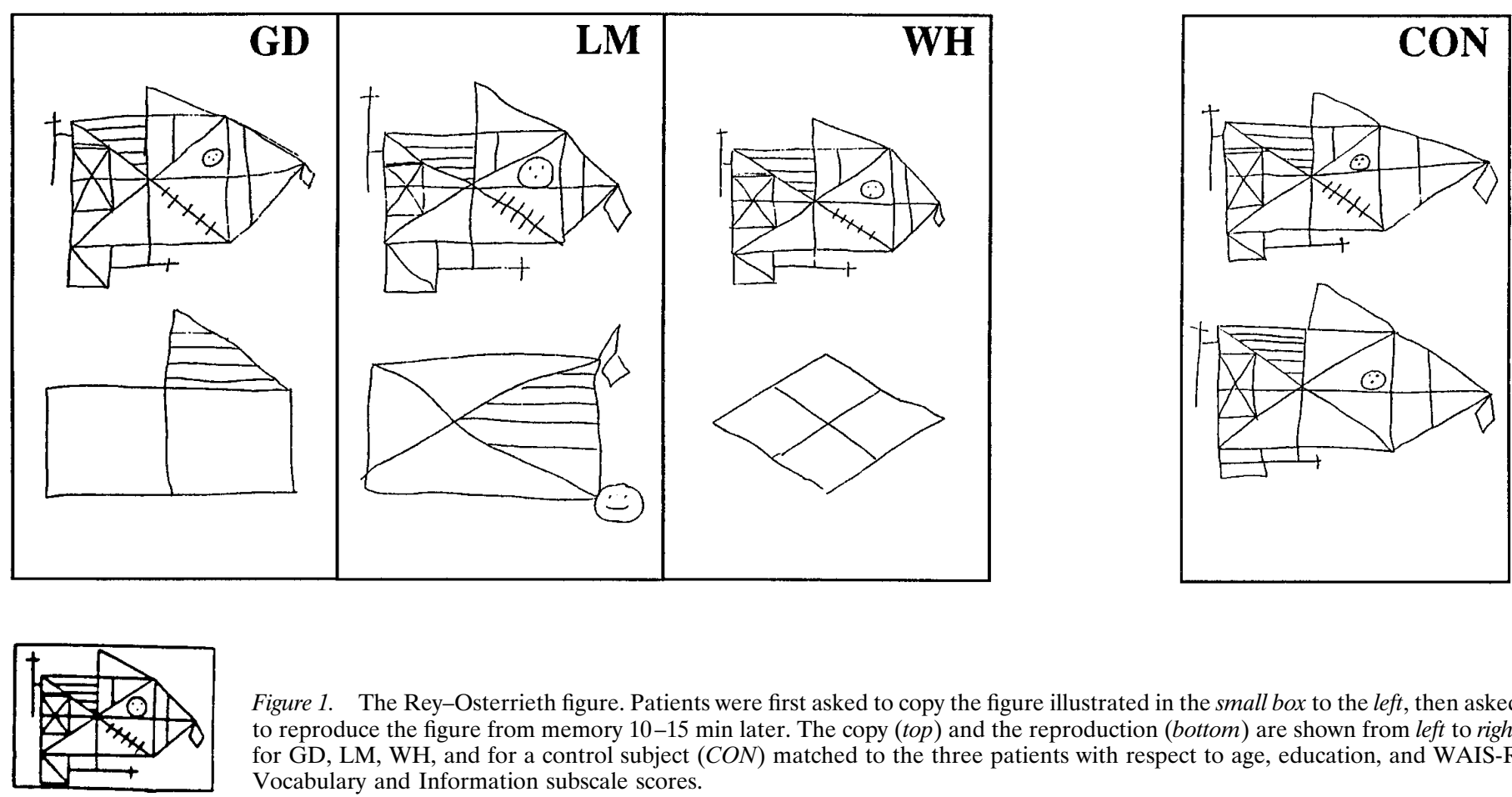

Figure 1. The Rey-Osterrieth figure. Patients were first asked to copy the figure illustrated in the small box to the left, then asked to reproduce the figure from memory 10-15 min later. The copy (top) and the reproduction (bottom) are shown from left to right for GD, $\mathrm{LM}, \mathrm{WH}$, and for a control subject $(\mathrm{CON})$ matched to the three patients with respect to age, education, and WAIS-R Vocabulary and Information subscale scores.

al., 1988; MacKinnon and Squire, 1989; Squire et al., 1989) (Patient LM is designated patient MRL in Beatty et al., 1987a). Figure 2 shows the performance of GD, LM, and WH on tests of remote memory for public events and famous faces. The control group scores presented here are from Squire et al. (1989). For the public events test, subjects were asked to recall 92 news events that occurred from 1950 to 1985 . For the famous faces test, subjects were asked to identify 117 photographs of famous people who had come into prominence between 1940 and 1985. The percent correct scores obtained by normal subjects on these tests exhibit considerable variability (scores for each decade varied by 33-57 percentage points for the public events test and 33-50 percentage points for the famous faces test). Accordingly, rather than consider only percent correct performance scores, one useful way to describe the performance of individual patients is to determine the pattern (or slope) of performance across decades. The mean slope for the eight control subjects on the public events test was 0.95 (range, -5.73 to $9.10, \mathrm{SD}=5.1$ ), and on the famous faces test it was 1.19 (range, -3.99 to $7.23, \mathrm{SD}=4.1$ ). By this analysis, LM and WH clearly exhibited a different pattern of retrograde memory across decades than the control subjects, with better memory for remote events and famous faces and poorer memory for recent events and famous faces (LM's slope for public events $=13.43$, famous faces $=13.98$; WH's slope for public events $=6.17$, famous faces $=10.74)$.

For LM and WH, corroborative information about their retrograde amnesia comes from earlier, independent assessments using tests of public events and famous faces very similar to the ones used here (Beatty et al., 1987a; Salmon et al., 1988). LM exhibited retrograde amnesia covering at least 15 years (Beatty et al., 1987a). He performed a little better than normal subjects for the period before 1950, about average for the 1950s and 1960s, and was deficient for the period after 1970. LM's absolute scores and the pattern of his performance, as reported by Beatty et al. (1987a), are very similar to the findings reported here from our own tests (Fig. 2). However, our control subjects performed somewhat more poorly than the control subjects tested by Beatty et al. (1987a).

WH was also given tests of public events and famous faces before our own assessment (Salmon et al., 1988). In full agreement with our findings (Fig. 2), Salmon et al. (1988) reported that WH performed normally or close to normal for the period before 1960 and that he was impaired for later time periods, especially the 1970 s and 1980 s.

GD's performance on the tests of public events and famous faces is more difficult to interpret (Fig. 2). He performed poorly on the tests, but he was also less well educated than the other subjects, he had a lower IQ (92), and he often seemed poorly motivated. The slope analysis did not suggest temporally graded retrograde amnesia in the case of the famous faces test (slope = 1.68). For the public events test, the slope was 9.00, but it was determined by a single point (the 1950s). Thus, it was difficult to determine from these two tests whether GD had extensive retrograde amnesia, or whether his scores were simply low because of his lower motivation and intellectual abilities.

Figure 3 shows the distribution of autobiographical memories produced in response to 75 single-word cues (additional data for GD, LM, and WH were published previously) (MacKinnon and Squire, 1989). Words were presented one at a time, and subjects were asked to describe an autobiographical recollection in response to each word (Crovitz and Schiffman, 1974). At the end of each test session, subjects were asked to date the remembered episodes. Normal middle-aged subjects typically exhibit a U-shaped temporal distribution of memories (McCormick, 1979). That is, they draw memories predominantly from the recent past and from the remote past, and they draw fewer memories from the middle of their lives. Patient GD selected episodes from both recent and more remote decades in a pattern similar to that observed for normal subjects. He showed no evidence of retrograde amnesia. These findings suggest that GD's poor performance on the public events and famous faces tests was attributable not to retrograde amnesia, but to not knowing the 
PUBLIC EVENTS
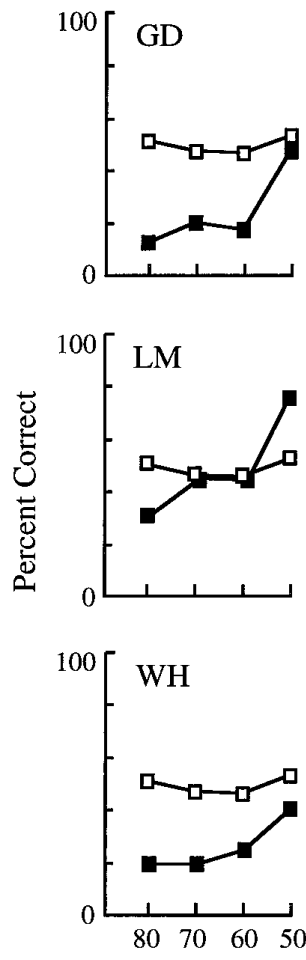

Decade
FAMOUS FACES
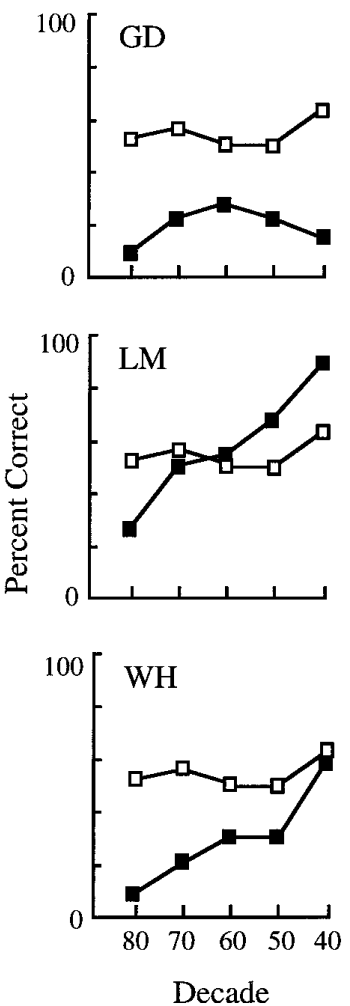

Figure 2. Individual scores for GD, LM, and $\mathrm{WH}$ on recall tests involving public events and famous faces. For comparison, the mean scores for control subjects $(n=8)$ are shown in open squares in each panel. In the public events test, SEs for the control subjects ranged from 3.9 to $7.1 \%$. For the famous faces test, SEs for the control subjects ranged from 4.4 to $5.5 \%$. The patients were tested in 1987; GD became amnesic in 1983, LM in 1984, and WH in 1986. Note that GD was born in 1940, so the personalities in the famous faces test for the 1940s came into prominence when he was younger than 10 years old. LM and $\mathrm{WH}$ had temporally graded retrograde amnesia (see Results). Also, see Results for discussion of the difficulty of interpreting GD's scores for these tests.

information covered in the tests. This possibility is also supported by GD's low WAIS-R Information subtest score (16; see Table 1). LM and $\mathrm{WH}$, however, produced autobiographical episodes mostly from before 1950, and produced very few recollections from the period after 1960 .

Finally, for LM, an additional measure of retrograde amnesia for personal memories comes from an earlier independent assessment with a test that asked him to draw floor plans of homes he had lived in throughout his life (Beatty et al., 1987a). LM's drawings of early homes were accurate (floor plans were verified by family members), but the most recent of his past residences that he could draw accurately was the house he had lived in from 1968 to $1970,14-16$ years before the onset of his amnesia. He was unable to reconstruct floor plans for the 12 homes in which he had lived from 1970 to 1984. In fact, he failed even to report six of these residences and could remember little about the others. The findings from the available retrograde memory tests, taken together, indicate that LM and WH both had extensive, temporally graded retrograde amnesia that extended back at least 15 years for LM and probably involved as much as 25 years for WH (Figs. 2 and 3).

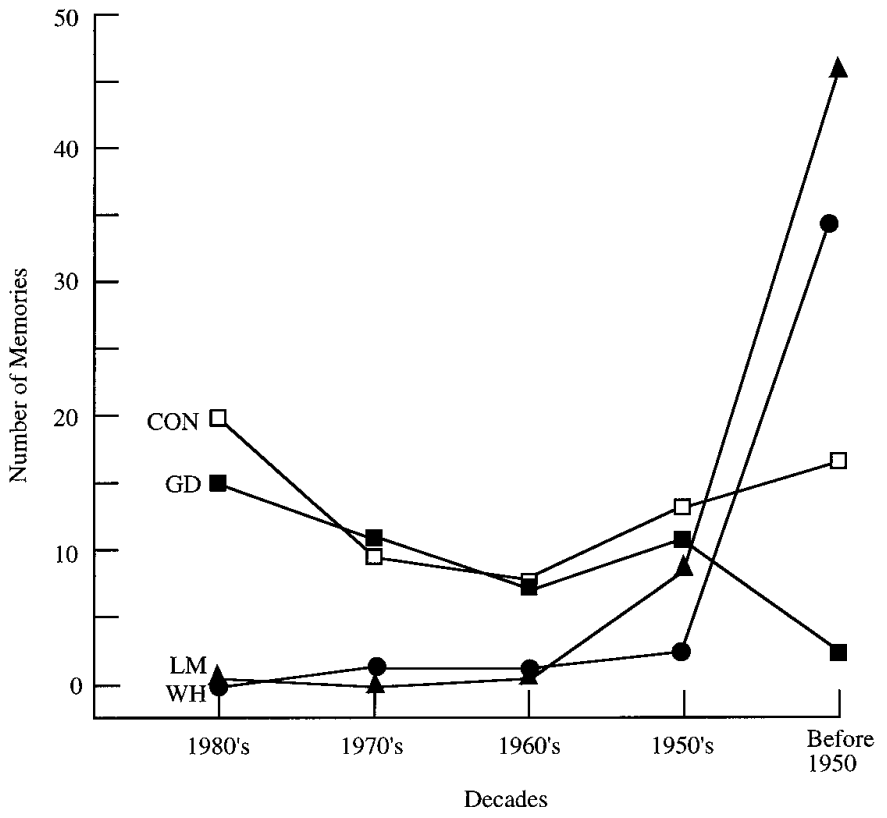

Figure 3. Time periods from which subjects drew their autobiographical memories in response to 75 single-word cues. The temporal distribution of recollections is shown for patients GD, $\mathrm{LM}, \mathrm{WH}$, and for a group of five normal control subjects $(C O N)$. Of 75 possible recollections, GD had 46, LM had 56, and WH had 45. Control subjects had a mean of 65.2 responses (range, 51-71). Note that GD was born in 1940, so the Before 1950 time point represents episodes that occurred when he was younger than 10 years old.

\section{Performance on other cognitive tests}

The memory impairment of these three amnesic patients occurred in isolation from other cognitive deficits. First, the patients obtained scores in the normal range on the WAIS-R (Table 1). In addition, they were tested on the Dementia Rating Scale (Mattis, 1976), which includes subscales for attention, initiation and perseveration, construction, conceptualization, and memory. Excluding the memory subscale, the amnesic patients scored as well as control subjects $(\mathrm{GD}=116 ; \mathrm{LM}=116 ; \mathrm{WH}=116$; mean of 11 control subjects $=115.3$, control group from Janowsky et al., 1989).

The amnesic patients were also given the Boston Naming Test (Kaplan et al., 1983), the Wisconsin Card Sorting Test (Heaton, 1981), the Parietal Lobe Battery (Goodglass and Kaplan, 1972), and the Verbal Fluency Test (Benton and Hamsher, 1976). On the Boston Naming Test, which asks subjects to provide the names of line drawings of 60 objects, the amnesic patients performed well: $\mathrm{LM}=52$; GD and $\mathrm{WH}=58$ (mean score for 6 control subjects $=$ 55.8; control subjects from Squire et al., 1990). In the Wisconsin Card Sorting Test, each patient sorted the maximum number of categories (6), showing no evidence of frontal lobe dysfunction. Similarly, GD, LM, and WH performed well on the Parietal Lobe Battery, scoring 93, 96, and 95\% correct, respectively.

The Verbal Fluency Test is considered sensitive to frontal lobe dysfunction and requires subjects to provide as many words as possible in 1 min beginning with the letter $\mathrm{F}$ (and then $\mathrm{A}$ and $\mathrm{S}$ ). Patients LM and WH performed as well as control subjects $(\mathrm{LM}=34, \mathrm{WH}=57$, mean of 6 control subjects $=37.5$; Squire et al., 1990). Patient GD's score on the Verbal Fluency Test was 22 , lower than any of the control subjects (range, 30-55). This score is difficult to interpret unambiguously in view of his good 
Table 3. Summary of neuropsychological and neuropathological findings from four patients with bilateral damage to the hippocampal formation

\begin{tabular}{llll}
$\begin{array}{l}\text { Anterograde } \\
\text { amnesia }\end{array}$ & $\begin{array}{l}\text { Retrograde } \\
\text { amnesia }\end{array}$ & $\begin{array}{l}\text { Damage to the hippocampal } \\
\text { formation }\end{array}$ \\
\hline RB & Moderate & Minimal & CA1 field \\
GD & $\begin{array}{l}\text { Moderate } \\
\text { LM }\end{array}$ & $\begin{array}{l}\text { Moderate } \\
\text { Extensive }\end{array}$ & $\begin{array}{l}\text { CA1 field } \\
\text { CA1, CA2, CA3 fields, dentate } \\
\text { gyrus, entorhinal cortex }\end{array}$ \\
WH & Severe & Extensive & $\begin{array}{r}\text { CA1, CA2, CA3 fields, dentate } \\
\text { gyrus, subiculum, entorhinal cortex }\end{array}$
\end{tabular}

GD and RB had damage restricted primarily to the CA1 field of the hippocampus bilaterally. GD and RB additionally had cell loss in the region of the CA1/subiculum border. LM, in addition to substantial cell loss in the dentate gyrus and all cell fields of the hippocampus, evidenced some loss of cells in layers II and III of entorhinal cortex. WH sustained more distributed damage to the hippocampal region overall than the other patients, including considerable loss of cells in the subiculum, complete loss of polymorphic cells in the dentate gyrus, and dispersion of the granule cell layer in the dentate gyrus. In addition, WH sustained cell loss in layers III, V, and VI of entorhinal cortex (slight cell loss also occurred in layer II of entorhinal cortex). The severity of memory impairment correlated with the extent of damage to the hippocampal formation. Thus, RB and GD had moderate anterograde amnesia and minimal retrograde amnesia. (The question mark for GD indicates that some uncertainty remains about the interpretation of his performance on remote memory tests.) LM had moderate anterograde amnesia, together with extensive, temporally graded retrograde amnesia covering at least 15 years. WH had severe anterograde amnesia together with extensive, temporally graded retrograde amnesia that was probably more severe than in LM and involved as much as 25 years.

performance on other tests sensitive to frontal lobe dysfunction or language impairment (the Wisconsin Card Sorting Test, the Initiation-Perseveration subtest of the Dementia Rating Scale, or the Boston Naming Test). GD often seemed uncooperative, depressed, and uninterested in testing. Although he was not tested on occasions when he was clearly uncooperative, his frequent low motivation during testing sessions made it difficult to interpret low scores (see Retrograde amnesia tests, above).

Finally, as with other amnesic patients, GD, LM, and WH performed normally on many tests of implicit (nondeclarative) memory. GD participated in four studies of implicit memory, including tests of word priming (Squire et al., 1987; Shimamura and Squire, 1989), cognitive skill learning (Squire and Frambach, 1990), and artificial grammar learning (Knowlton et al., 1992). Patient LM participated in eight different studies of implicit memory, including word priming (Shimamura and Squire, 1989; Musen and Squire, 1993); picture priming and priming of novel nonverbal material (Cave and Squire, 1992; Musen and Squire, 1992); facilitated reading speed for words and nonwords (Musen et al., 1990; Musen and Squire, 1991); cognitive skill learning (Squire and Frambach, 1990); and adaptation level effects (Benzing and Squire, 1989). WH was involved in four studies of implicit memory: tests of word priming (Shimamura and Squire, 1989), artificial grammar learning (Knowlton et al., 1992), prototype learning (Knowlton and Squire, 1994), and probabilistic classification learning (Knowlton et al., 1994). Patients GD, LM, and WH performed as control subjects did in each of these studies. In one study of word-stem completion priming, in which all three patients participated (Shimamura and Squire, 1989), the three patients averaged $20.0 \%$ priming (different context condition: $\mathrm{GD}=25.0 \%, \mathrm{LM}=20.0 \%, \mathrm{WH}=15.0 \%)$, and the control group $(n=28)$ averaged $18.6 \pm 2.0 \%$.

To summarize (Table 3 ), patient GD had moderately severe anterograde amnesia. Although his retrograde memory performance was mixed, it seems unlikely that he had extensive temporally graded retrograde amnesia. Thus, his memory impairment appeared similar to that of RB (Zola-Morgan et al., 1986). LM's anterograde amnesia seemed roughly similar to that of GD and $\mathrm{RB}$, but he had more severe, temporally graded retrograde amnesia that covered at least 15 years. Finally, WH had more severe anterograde amnesia than either GD, LM, or RB, and he had severe, temporally graded retrograde amnesia involving as much as 25 years. None of the patients exhibited any cognitive impairment other than amnesia.

\section{Neuropathological findings}

\section{Gross appearance of the brains}

The surfaces of all three brains were examined before further histological processing. No infarcts or general cortical atrophy were apparent. In the brains of LM and WH, who died at the ages of 60 and 71, respectively, there appeared to be some slight widening of sulci, which is frequently observed with aging (Tomlinson et al., 1968). There was, however, no evidence of the dramatic cortical atrophy that is seen with Alzheimer's disease (Tomlinson et al., 1970). GD died at the younger age of 52 and his brain did not exhibit sulcal widening. In GD and LM, the mammillary nuclei appeared normal in shape and size (for GD, see additional information about mammillary nuclei, below). For LM, the volume of this region had been calculated as normal in a previous magnetic resonance (MR) study (Squire et al., 1990). WH's mammillary nuclei appeared to be somewhat smaller than normal, also in agreement with earlier MR findings (Squire et al., 1990).

\section{Microscopic appearance of the brains}

All three patients had bilateral damage to the hippocampal formation. Minimal additional damage occurred in other brain regions. Before describing the brains of the patients, we first review briefly the normal appearance of the human hippocampal formation (for review, see Insausti et al., 1995; Amaral and Insausti, 1990).

Normal appearance of the human hippocampal formation. The hippocampal formation includes the dentate gyrus, the hippocampus proper, the subicular complex, and the entorhinal cortex (Fig. 4). The human dentate gyrus has three layers: the granule cell layer, the molecular layer, and the polymorphic layer, or the hilus. In Nissl-stained tissue, the polymorphic cells are difficult to distinguish from pyramidal cells of the hippocampus, but in other preparations (i.e., Timm's stain or acetylcholinesterase stain) this region shows a distinct pattern of labeling. The hippocampus can be divided into three distinct fields, designated CA1, CA2, and CA3 according to the nomenclature of Lorente de Nó (1934). Field CA3 borders the hilus of the dentate gyrus, where it is enclosed by the granule cell layer. The CA2 region contains a more narrow and compact pyramidal cell layer and is particularly resistant to neuropathology (Brierley and Graham, 1984). The CA1 region begins where the pyramidal cell layer broadens, and is thickest just before the border of CA1 and the subiculum. The CA1 field and the subiculum overlap at their border, which is oriented obliquely to the cell fields.

The entorhinal cortex is multilaminate and is considered to comprise six layers [modification of the nomenclature of Ramon y Cajal (1901-1902)] (Insausti et al., 1995). Briefly, layer I is a plexiform layer, layer II contains islands of large, darkly staining cells, and layer III is broader and consists of medium-sized pyramidal cells. Entorhinal cortex lacks an internal granular layer IV, but at midrostrocaudal levels has an acellular region, lamina dissecans (Rose, 1927), in place of a granular layer. This acellular 
Figure 4. Coronal section from a normal brain through the right rostral hippocampal formation stained with thionin. Arrows mark the borders between regions. $C A 1$ and $C A 2 / 3$ refer to the $C A$ fields of the hippocampus. $D G$, Dentate gyrus; $m l$, molecular layer of the dentate gyrus; $g l$, granule cell layer; $p l$, polymorphic layer; $S$, subiculum; $\operatorname{Pr} S$, presubiculum; $P a S$, parasubiculum; $E C$, entorhinal cortex; cs, collateral sulcus; $P R C$, perirhinal cortex. Scale bar, $1 \mathrm{~mm}$.

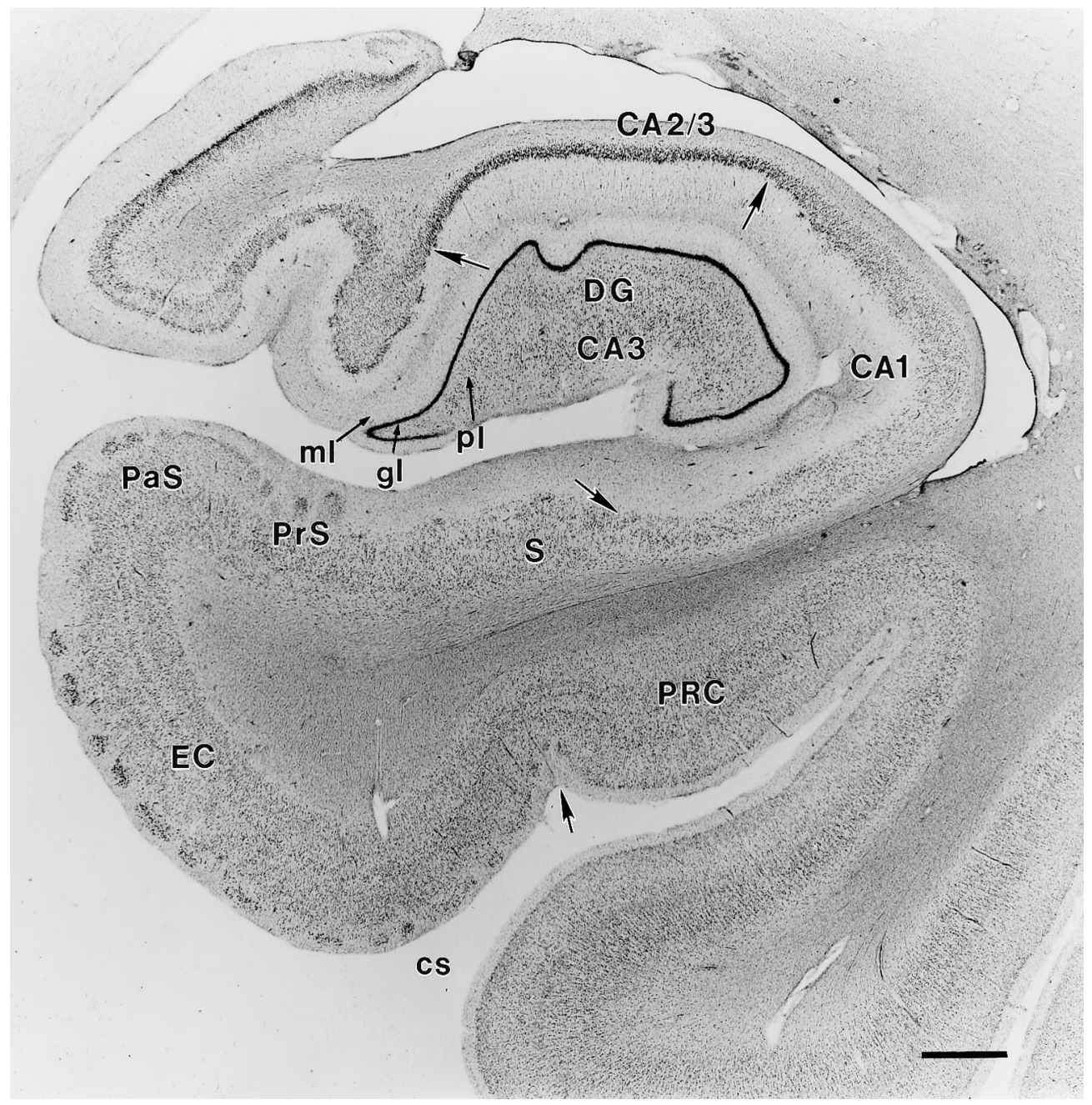

region is referred to as layer IV of entorhinal cortex. Layer V contains large, dark pyramidal cells and is approximately 5-6 cells deep. Finally, layer VI is more heterogeneous and is difficult to distinguish from layer $\mathrm{V}$ in rostral entorhinal cortex, although a border between layers V and VI is identifiable in caudal entorhinal cortex.

\section{Patient $G D$}

Medial temporal lobe. GD had a bilateral lesion of the hippocampal region involving most of the CA1 field throughout its rostrocaudal extent (Figs. 5, 6, 13, 14). Extensive bilateral loss of CA1 pyramidal cells was observed, and the area of the CA1 field was reduced. Some proximally situated CA1 pyramidal cells remained bilaterally at midrostrocaudal and caudal levels of the hippocampus. An increase in the density of glial cells was evident throughout CA1, especially in the stratum oriens and stratum radiatum, the regions above and below the region usually occupied by the pyramidal cells (see Fig. 6). Increased vascularization, particularly adjacent to the hippocampal fissure, was apparent in occasional sections throughout the rostrocaudal extent of the hippocampus (for example, see Fig. 6A). No cell loss was observed in the CA2 or CA3 fields at any level of the hippocampus.

There was also some subicular cell loss bilaterally in the area of the subiculum/CA1 border, with more loss evident on the left side (Fig. $6 C-F$ ). This cell loss was more pronounced caudally. No damage was observed in any of the layers of the dentate gyrus.
Sections stained with a modified Heidenhain fiber procedure demonstrated that the alveus, which runs below the pyramidal cell layer of CA1, was apparently intact. Fibers of the perforant path, which originates in the entorhinal cortex, could be seen passing through the CA1 field to terminate in the dentate gyrus and CA3 field. The fimbria appeared to be slightly shrunken on the left side, although no gliosis was observed in the sections stained with thionin.

The entorhinal cortex receives approximately two-thirds of its cortical input from the adjacent perirhinal and parahippocampal cortices (Insausti et al., 1987). Damage to these cortical areas has been associated with memory impairment. Accordingly, these areas were examined carefully. The borders between the entorhinal, perirhinal, and parahippocampal cortical areas were easily distinguishable in patient GD, and no cell loss was evident in any of these areas. The left entorhinal cortex appeared to have some very slight cell loss in layers III and V. Otherwise, all cortical layers had an apparently normal cell density. The amygdala appeared normal on the right side, but had a small region of gliosis in the ventromedial portion of the left side.

Diencephalon. Damage to medial diencephalic structures, including the anterior nucleus, internal medullary lamina, mediodorsal nucleus, and other midline nuclei of the thalamus, as well as the mammillary nuclei, has been associated with memory impairment (Markowitsch, 1988; Mayes, 1988; Victor et al., 


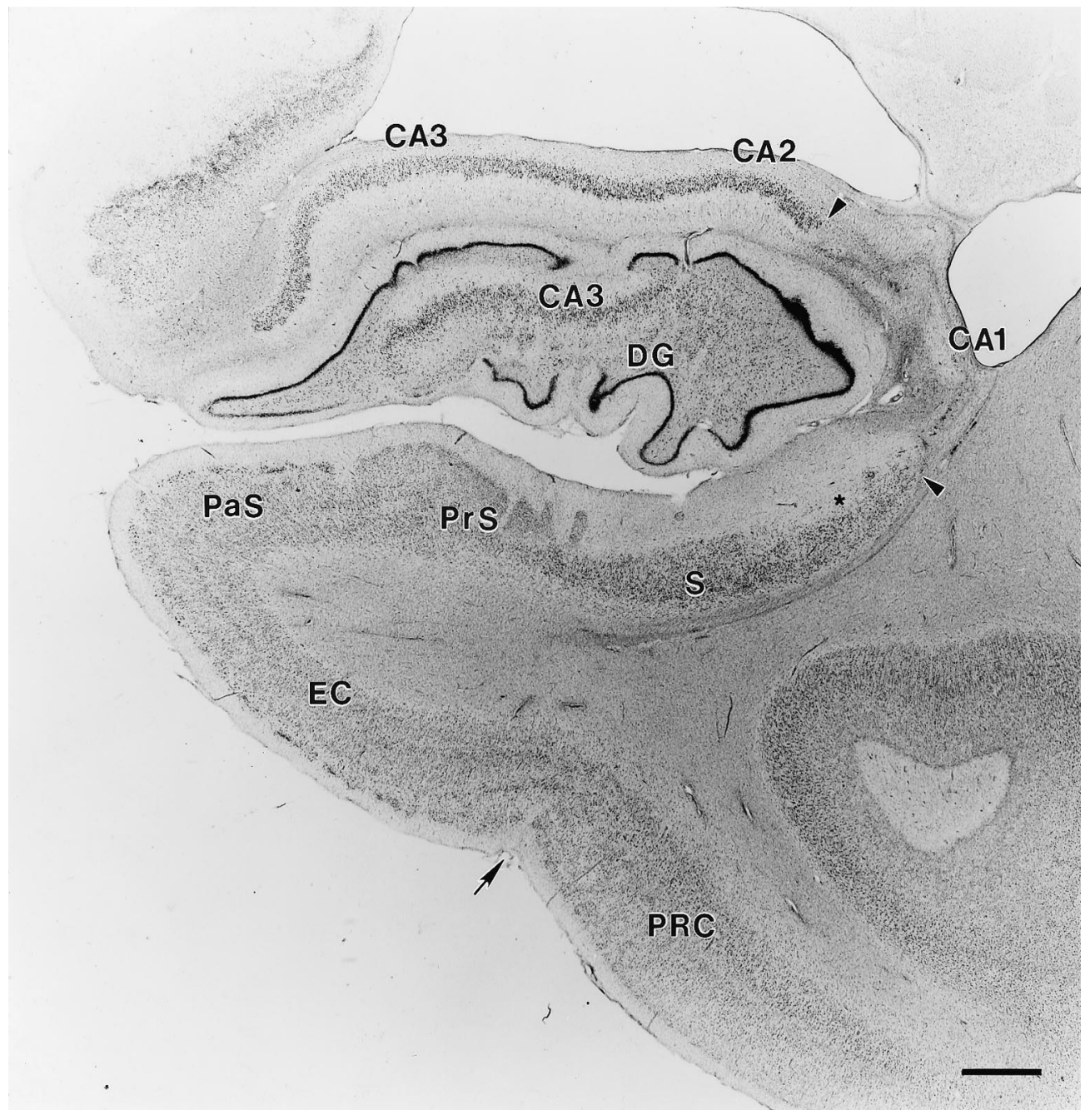

Figure 5. Coronal section through GD's right rostral hippocampal formation stained with thionin. Region of total pyramidal cell loss in the CA1 field is marked with arrowheads. No cell loss is evident in the CA2 or CA3 fields, the dentate gyrus, or entorhinal cortex. Star indicates an area of slight cell loss in proximal subiculum. An arrow indicates the border between the entorhinal and perirhinal cortex. Abbreviations as in Figure 4. Scale bar, $1 \mathrm{~mm}$.
1989; Graff-Radford et al., 1990; Zola-Morgan and Squire, 1993). Thus, particular attention was given to these areas in the analysis of the diencephalon. In GD's brain, the left medial mammillary nucleus demonstrated some cell loss, and the lateral half of the nucleus was particularly pale. On the right side, the mammillary nucleus was normal in size and shape. There were no areas of cell loss in the right thalamus, but the left side showed some very small regions of decreased cell density. Specifically, the left mediodorsal thalamic nucleus appeared to have a slight loss of medial magnocellular cells relative to the right side. The left fornix appeared smaller than the right, but, in general, the fornix and the mammillothalamic tract appeared normal in sections stained using the Heidenhain fiber procedure.

Other areas. Sections were examined from all major cortical areas. A few small acellular foci were observed in the neocortex, including one in the polar cortex of the left temporal lobe, a few bilaterally in anterior lateral temporal cortex, and three in the occipital lobe. Otherwise, the cortex had a normal appearance. All cortical layers were present throughout cortex, with no apparent decrease in cell density in any area other than those mentioned above.

Throughout the white matter, there were small holes, which appeared to be enlargements of the perivascular space, i.e., Virchow-Robin space (Braffman et al., 1988). They are seen frequently at autopsies and are most commonly associated with hypertension, although they are sometimes found in association with normal blood pressure (Cole and Yates, 1968). Numerous areas of perivascular dilation were noted bilaterally in the temporal poles and near the claustrum in the temporal stem.

An infarct was observed in the lateral segment of the right globus pallidus that appeared to extend $\sim 7 \mathrm{~mm}$ rostrocaudally and $\sim 2 \mathrm{~mm}$ in width at its widest point. The lesion consisted of a region of cell loss and degeneration surrounded by a dense band of gliosis. The cerebellum showed no evidence of damage other than a small area of ischemic cell loss in the vermis. Damage to the basal forebrain has been implicated in some cases of amnesia (Alexander and Freedman, 1984; Damasio et al., 1985; Phillips et al., 1987; Morris et al., 1992). However, no evidence of damage was noted in the basal forebrain, including the septal nuclei, nucleus accumbens, substantia innominata, nucleus of the diagonal band, and nucleus basalis of Meynert.

\section{Patient LM}

Medial temporal lobe. The primary finding in LM's brain was an extensive bilateral lesion of the hippocampal region (Figs. 7, 8, 13, 14) with somewhat more severe damage on the left side than on the right. There was nearly complete bilateral loss of the CA1 pyramidal cells, with only a small portion of the distal part of the 

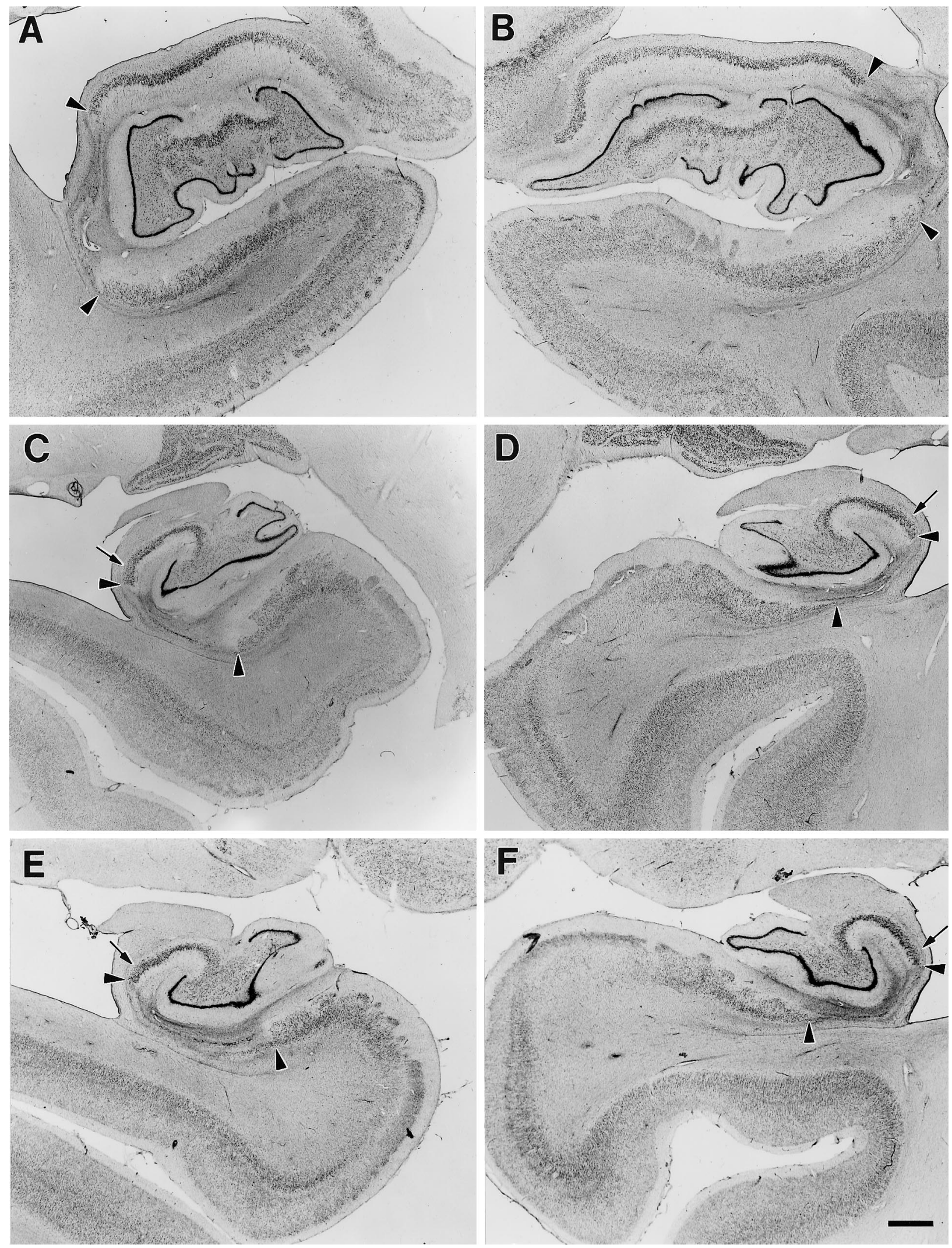

Figure 6. Coronal sections through the left and right sides of GD's hippocampal formation at rostral $(A, B)$, mid $(C, D)$, and caudal $(E, F)$ levels. Region of pyramidal cell loss is marked with arrowheads at each level. The lesion includes most of CA1 and proximal subiculum, with more subiculum damage on the left side. Note the sparing of proximal CA1, particularly in the caudal hippocampal region (small arrows in $C-F$ ). At these caudal levels, more of the proximal subiculum is damaged. Scale bar, $1 \mathrm{~mm}$. 


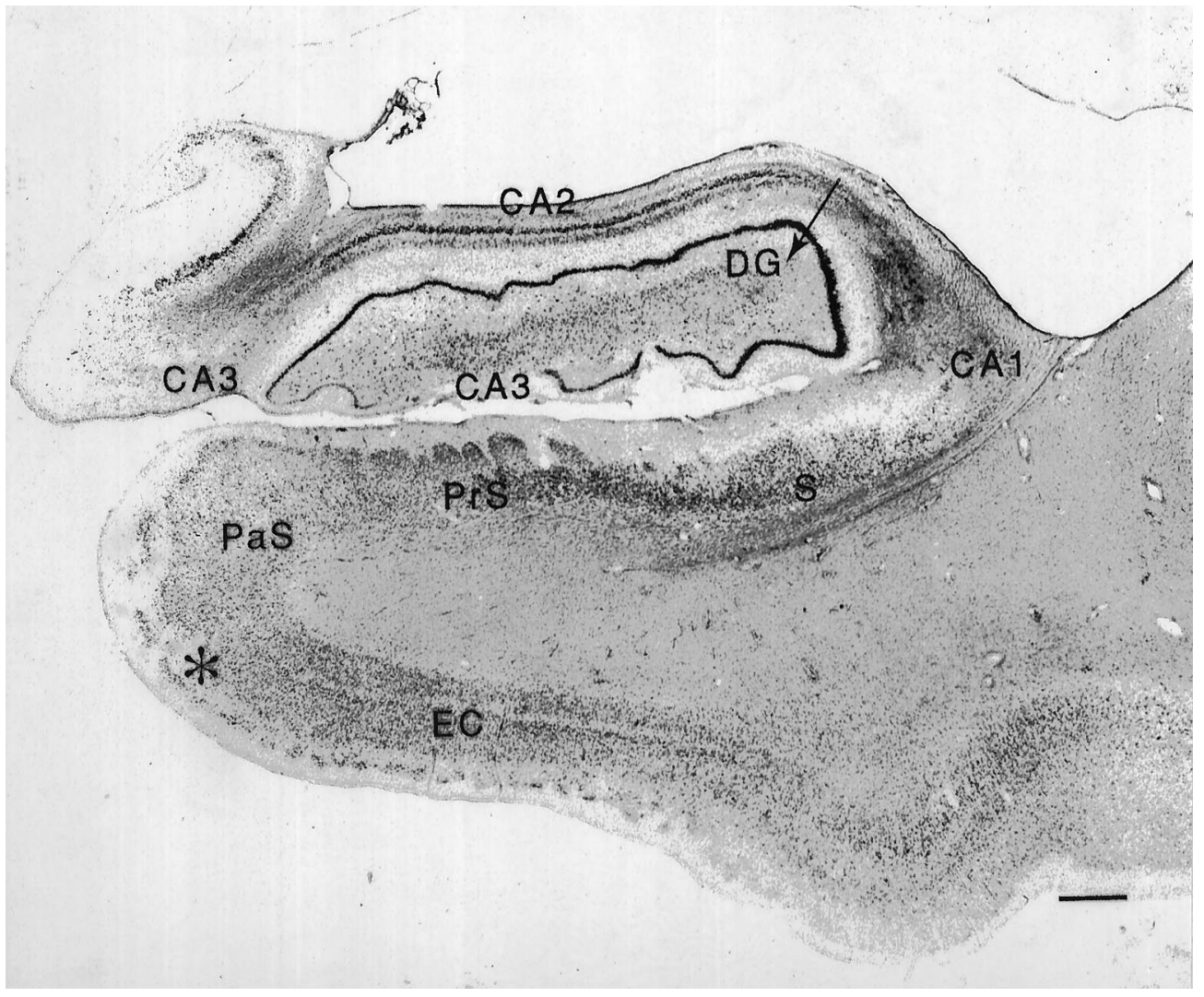

Figure 7. Coronal section through LM's right rostral hippocampal formation. Note the complete loss of CA1 pyramidal cells and the extensive loss of CA3 pyramidal cells (some CA3 cells remain distally). The CA2 field is partially intact. Extensive loss of polymorphic cells is evident in the hilus of the dentate gyrus (indicated by arrow). The subiculum and entorhinal cortex do not show any cell loss at this level. Abbreviations as in Figure 4. Asterisk indicates regions of faint staining, which are artifactual and are not areas of cell loss. Scale bar, $1 \mathrm{~mm}$. field remaining intact through the rostrocaudal extent of this field (Fig. 8). Throughout CA1, there was an increase in the density of glial cells. Increased vascularization, particularly associated with the hippocampal fissure, was apparent in occasional sections throughout the rostrocaudal extent of the hippocampal region (Fig. 8C).

The CA2 field also sustained damage, but there appeared to be some remnant of CA2 at most rostrocaudal levels of the hippocampus, bilaterally. There also was extensive loss of the pyramidal cells in the CA3 field bilaterally. Essentially complete bilateral CA3 pyramidal cell loss was observed through the rostral half of the hippocampal region. At progressively more caudal levels, there was a progressive increase in the length of CA3 with at least some pyramidal cells intact (Fig. 8). In both the CA2 and CA3 fields, the damage was more extensive in anterior than posterior hippocampus.

Patches of granule cell layer thinning were apparent in the dentate gyrus. Dentate granule cell loss was particularly notable on the left side (see Fig. $8 E$ ). Only the most caudal sections on both sides (not shown) appeared to have a completely normal complement of dentate granule cells. The molecular layer of the dentate gyrus also appeared to be somewhat thinner than normal. In addition, almost total cell loss was observed in the hilar region. Again, the loss of polymorphic cells was more extensive rostrally than caudally (note the loss of hilar cells in Fig. 7). The subiculum had a generally normal appearance at most levels through the hippocampal region, although there were patches of cell loss in its proximal portion (particularly evident in Fig. $8 E, F$ ). The thinning of the subiculum was more apparent on the right side than on the left.

Sections stained for myelinated axons demonstrated that the alveus was not affected by the pathology. Moreover, the perforant path was visible bilaterally at all rostrocaudal levels of the hippocampal region. Fibers of the perforant path could be seen to travel through CA1 to reach their normal termination in the dentate gyrus and the CA3 field of the hippocampus. The fimbria appeared slightly shrunken, but with little evidence of gliosis.

All layers of the entorhinal cortex were evident, but layers II and III appeared to have some cell loss bilaterally (Fig. $8 A, B$ ). The paucity of cells was particularly evident in the deep half of layer III. No obvious damage was detected in other medial temporal lobe cortical areas, including the perirhinal and parahippocampal cortices. The amygdaloid complex showed no evidence of cell loss. Overall, the lesion observed in LM's hippocampal formation was fairly symmetrical, although there was somewhat more damage to the left than to the right side.

Diencephalon. In LM, neither the mammillary nuclei nor the medial thalamic nuclei showed any signs of damage. The mammillary nuclei were normal in size and shape, and microscopically had a normal cell density. Volume measurements of LM's mammillary nuclei in a previous MRI study were in the range of normal subjects (Squire et al., 1989). There was no evidence of damage in the medial thalamic nuclei, and the medial dorsal nucleus had a normal appearance with no sign of gliosis. The fornix and mammillothalamic tract appeared generally normal in the fiber preparation, except for slight gliosis at the tip of the fornix; the entire fornix appeared bilaterally reduced in size.

Other regions. Sections were examined from all major cortical areas. The only significant area of cortical damage was an infarct in the right lateral occipitotemporal cortex (area 19 of Brodmann), extending $\sim 2 \mathrm{~cm}$ rostrocaudally and as wide as $2.5 \mathrm{~cm}$ mediolaterally. Damage in this area involved all layers of the cortex and the underlying white matter. A second, much smaller infarct was observed in the anterior left middle temporal sulcus 

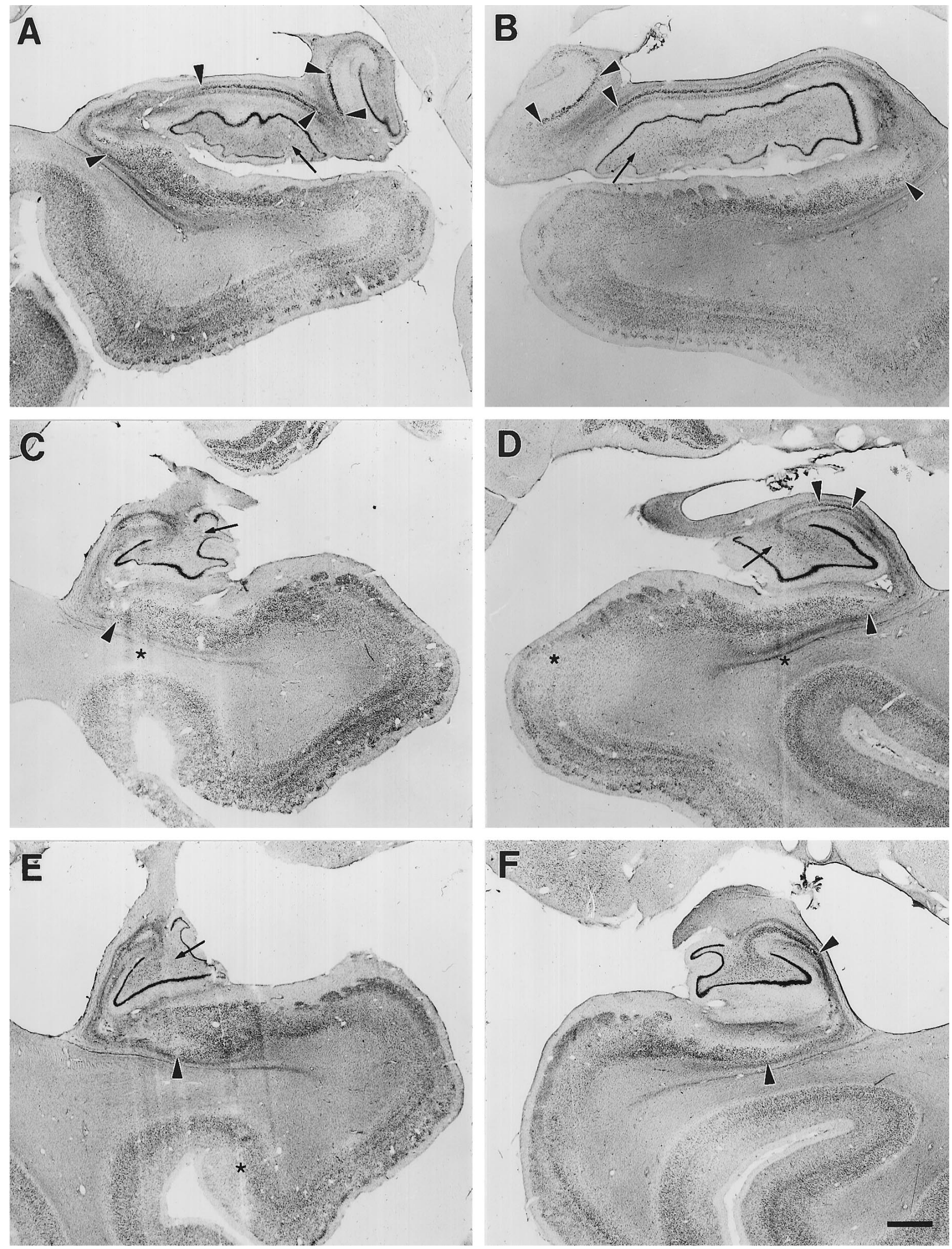

Figure 8. Coronal sections through the left and right sides of LM's hippocampal formation at rostral $(A, B)$, mid $(C, D)$, and caudal $(E, F)$ levels. Arrowheads mark borders between areas of preserved neurons and areas of pyramidal cell loss. The lesion includes the CA3 pyramidal cells and most of the CA1 field, sparing some distal CA1. Regions of extensive loss of polymorphic cells in the hilus are indicated with long arrows. Cell loss also is evident in some portions of the granule cell layer (see especially $A$ and $C$ ). Star indicates artifact attributable to cutting or staining of tissue. Scale bar, $1 \mathrm{~mm}$. 
and extended $\sim 8 \mathrm{~mm}$ rostrocaudally through all cortical layers. This infarct appeared quite narrow ( $<1 \mathrm{~mm}$ wide) and involved a small area of white matter directly below it. Much less white matter damage was associated with the infarct in the left medial temporal sulcus than in occipitotemporal cortex.

Small foci of cell loss, similar to but fewer in number than those described in patient RB (Zola-Morgan et al., 1986), were found distributed throughout the cortex. Twenty foci were counted in LM, with most located at the level of the amygdala and the anterior hippocampal region. Most of these acellular foci were very small (no more than $\sim 0.5 \mathrm{~mm}$ in width), involving only $2-3$ layers of cortex, although a few involved all layers of cortex.

Also found distributed throughout cortex were small hypercellular regions presumed to be metastases, secondary to LM's lung carcinoma. Multiple brain metastases are frequently observed with small-cell lung carcinoma (Hirsch et al., 1982), distributed more often in the frontal, parietal, and occipitotemporal regions than in the temporal or occipital lobes, and occasionally in the basal ganglia (Delattre et al., 1988). The metastases noted in LM's brain had a similar distribution ( 8 in frontal cortex, 11 in parietal cortex, 5 in temporal cortex, and 5 in occipitotemporal cortex). In addition, six metastases were observed in the basal ganglia (5 in the putamen and 1 in the claustrum). These metastases appeared as small, round areas of hyperintense staining. Most were $<0.5$ $\mathrm{mm}^{3}$, with the largest $\sim 1 \mathrm{~mm}^{3}$.

Overall, the cortex had a normal appearance. The layers of all cortical areas were evident, and there was no laminar necrosis as has been observed in cases of prolonged ischemia (Garcia and Conger, 1981; Plum, 1983). Furthermore, no decrease in cell density was apparent in any cortical area.

Substantial cell loss was noted in the medial septal nuclei of the basal forebrain, but no damage was detected in other basal forebrain areas, including the nucleus accumbens, substantia innominata, nucleus of the diagonal band, and nucleus basalis of Meynert. The striatum had a normal appearance. As frequently seen in cases of ischemia and anoxia, there was patchy loss of cerebellar Purkinje cells in the vermis. In addition, the right and left lobules of the cerebellum were mildly atrophic.

\section{Patient $W H$}

Medial temporal lobe. WH had an extensive bilateral lesion of the hippocampal formation (Figs. 10, 11, 13, 14) with somewhat more severe damage on the left side than on the right. Bilateral loss of CA1 pyramidal cells was observed, but more CA1 pyramidal cells were spared in $\mathrm{WH}$ than in $\mathrm{RB}, \mathrm{GD}$, or LM. The spared CA1 pyramidal cells were observed throughout the full transverse extent of the field; the preserved cells appeared to be those normally residing in the superficial portion of the layer (Fig. 11C). There was cell loss also in the CA2 field but less than in the CA1 and CA3 fields. Some pyramidal cells were present, bilaterally, at all rostrocaudal levels of the CA2 field. There was nearly complete loss of pyramidal cells in the CA3 field, bilaterally (Fig. 11). On the right side, some CA3 pyramidal cells remained in the most caudal levels of the hippocampus. Damage to the CA2 and CA3 fields was more extensive rostrally than caudally in the hippocampus. Holes were present in the CA 3 and CA1 fields that were also visible in WH's MR images (Fig. 12).

The appearance of WH's dentate gyrus was very abnormal bilaterally. Prominent holes appeared in the hilus of the dentate gyrus. Whereas some of these appeared to be enlarged blood vessels, others were infarcts or other defects in the hippocampal tissue. Essentially complete loss of hilar cells was noted (Fig. 11).
The granule cell layer did not have its normal tightly packed appearance. Rather, there was a radial dispersion of the granule cells that constituted the layer. Dispersion of the granule cells was prominent at most rostrocaudal levels, decreasing slightly at caudal levels. Because of the changes in the density of the granule cell layer caused by the dispersion, it was not clear whether there was actual cell loss. If there were actual cell loss, it would likely have been minimal. In addition to changes in the cell density and thickness of the granule cell layer, the granule cells appeared larger than normal with thickening of proximal dendrites. Similar pathology has been reported in patients with temporal lobe epilepsy (Houser et al., 1990) and in rats months after kainic acid lesions of the hippocampus (Suzuki et al., 1995). After finding this pathology in $\mathrm{WH}$, we reexamined his medical records and reinterviewed his wife regarding his seizures. We were able to document only the two seizures described previously, one in 1985 and one in 1988.

Patchy cell loss was observed in the subiculum. Cell loss in the subiculum was more pronounced caudally and greater on the left side than on the right (Fig. 11E,F). The fimbria was shrunken and gliotic bilaterally. The entorhinal cortex also appeared abnormal, but its pathology was slightly different than that seen in LM. At rostral levels of WH's entorhinal cortex, the lamina were clearly defined, although the distinctiveness of the layers decreased at more caudal levels. Cell loss in the entorhinal cortex was noted bilaterally in layers III, V, and VI, and slight loss was observed in layer II. The deep portion of layer III had the most apparent loss of neurons. The entorhinal cortex sustained more damage on the left side than the right (Fig. 11C). No damage was detected in the perirhinal and parahippocampal cortices.

Diencephalon. WH's mammillary nuclei were reduced in size, corresponding to findings from magnetic resonance studies performed 5 years before his death (Squire et al., 1990). Microscopically, the cells were more densely packed than normal, and mild gliosis was apparent (Fig. 15B). Gliosis was evident in the fornix as it entered the medial mammillary nuclei from their lateral aspect. Both of these observations are consistent with degeneration of the subiculum and loss of fibers directed to the medial mammillary nuclei. There was slight gliosis evident throughout the fornix and it appeared reduced in size. The thalamus showed no signs of damage.

Other areas. Overall, the cortex had a normal appearance with clearly defined lamina and no decrease in cell density apparent in any cortical area. Numerous areas of perivascular dilation were noted throughout the white matter of WH's brain. These were substantially more abundant and of larger size than those observed in GD. These lacunae were densely distributed especially in the temporal poles bilaterally, and subcortically in the striatum, claustrum, and the globus pallidus, particularly in its medial segment. The only other damage noted in the brain of WH was an infarct in the pons. The appearance of the cerebellum was normal with the exception of some loss of Purkinje cells in the vermis. No cell loss was noted in the basal forebrain.

\section{Summary of the three brains}

Patient GD had the least damage of the three patients. The primary lesion in GD's brain involved nearly all the CA1 field of the hippocampus bilaterally, sparing a small portion of proximal CA1, and also included a small region of the subiculum near the CA1 border. No bilateral damage was identified elsewhere in the hippocampal region or in the entorhinal, perirhinal, or parahippocampal cortices. Other than in the medial temporal lobe, there 


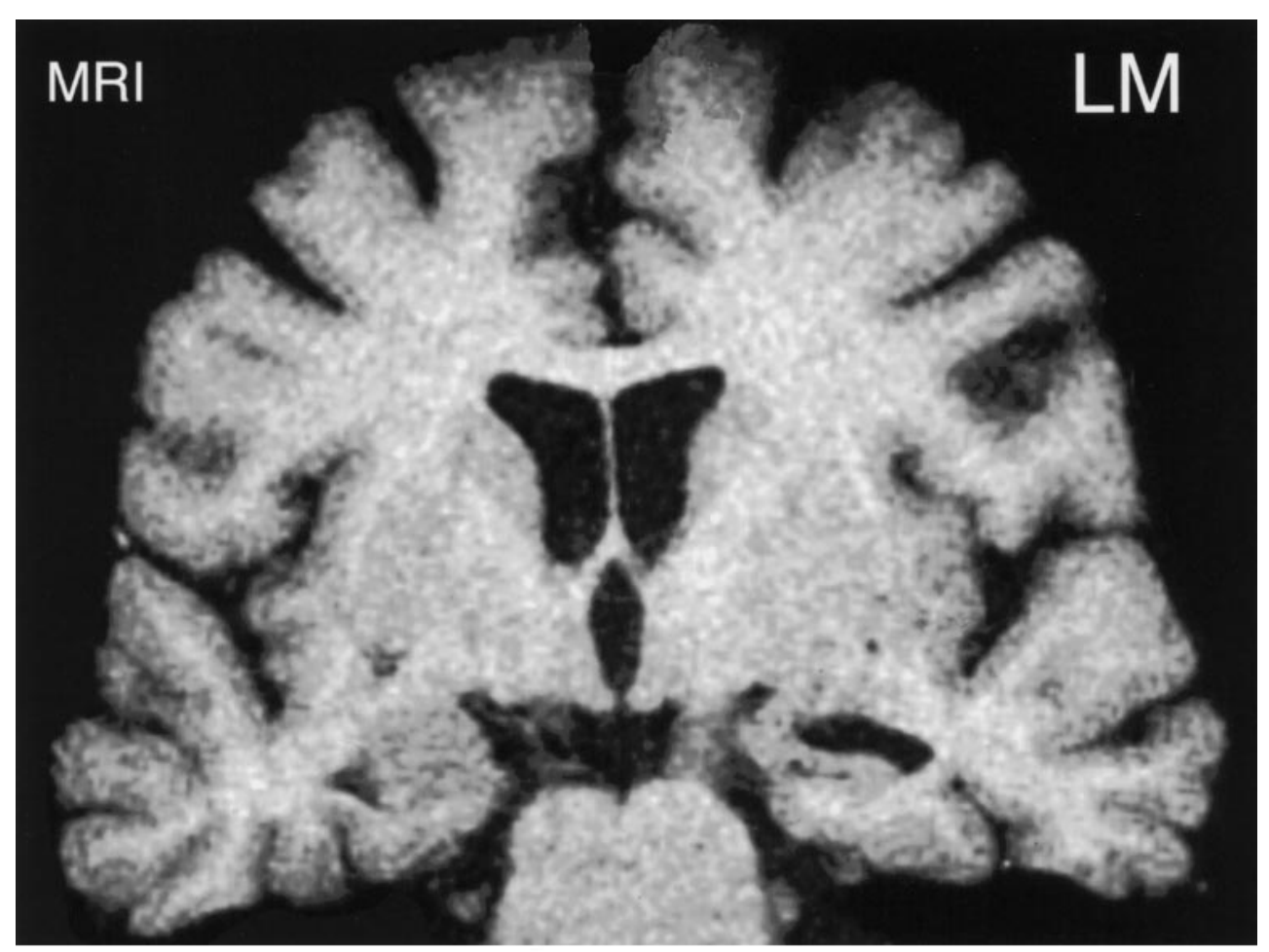

Figure 9. Comparison of a T1-weighted MRI (top) and a Nissl-stained histological section (bottom) from the brain of patient $\mathrm{LM}$ at the level of the mammillary nuclei $(M M N)$. The brain appeared to be somewhat asymmetrical because the amygdaloid complex $(A)$ is seen on the left side, whereas the hippocampus $(H)$ is seen on the right. The asymmetry does not appear to be attributable to oblique coronal sectioning because the mammillary nuclei are apparent bilaterally. Note the enlarged ventricle located dorsal to the hippocampus on the right side and the markedly shrunken appearance of the hippocampus. There is a clear correspondence in the appearance of the hippocampal formation in the MRI and in the histological section. The entorhinal cortex $(E C)$ also is visible bilaterally. The right side of the brain is shown on the right side of the illustrations.

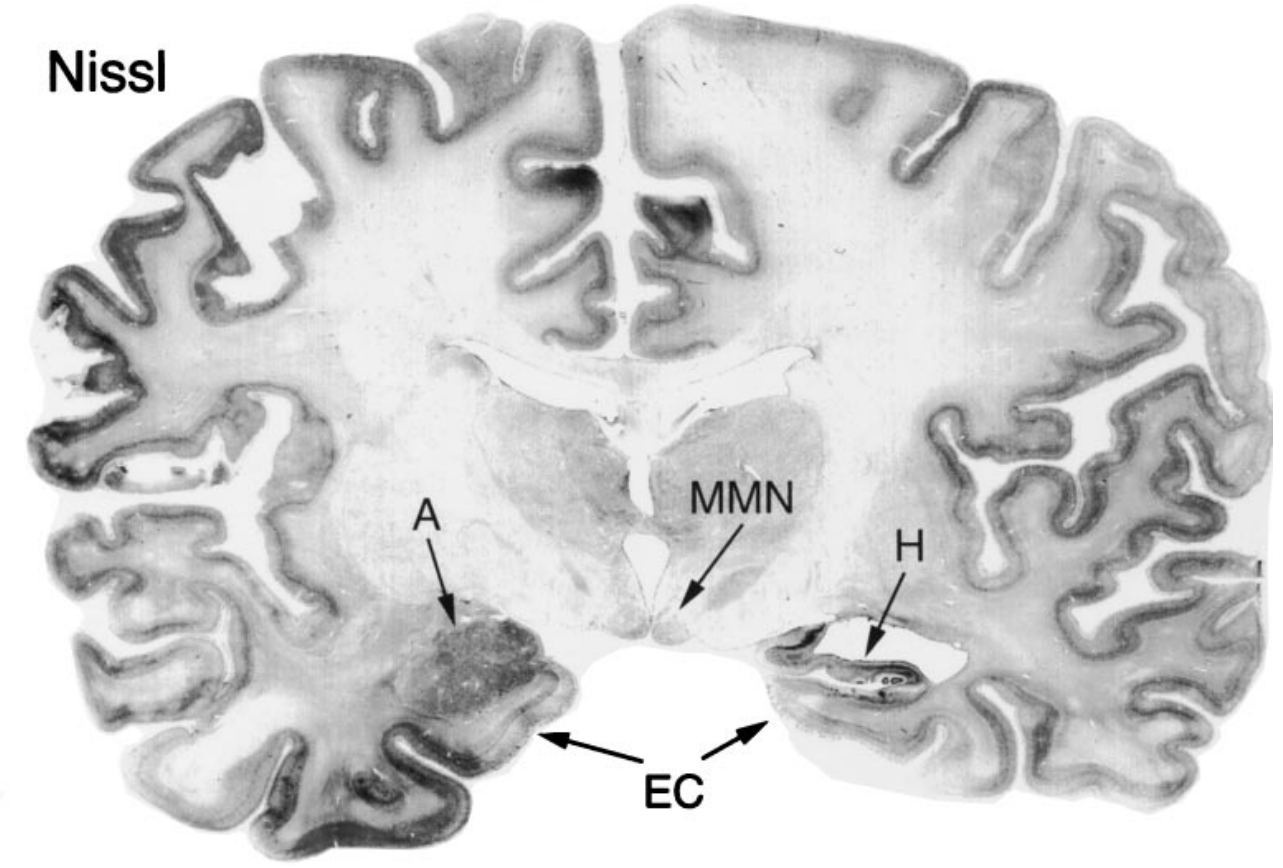

was minimal damage to the left medial mammillary nucleus and the left mediodorsal nucleus of the thalamus. There was no evidence of damage in the basal forebrain. Damage was also detected in the external segment of the right globus pallidus, and enlarged perivascular spaces were noted in a widespread distribution throughout the white matter.

Patient LM had more damage to the hippocampal formation than GD. His lesion included most of the CA1 field bilaterally, sparing the most distal portion of the field near the subiculum border. The CA2 field sustained some damage, but there were patches of preserved CA2 throughout the rostrocaudal length of the hippocampus. In addition, there was essentially complete loss of CA3 pyramidal cells bilaterally. Loss of the CA2 and CA3 pyramidal cells was generally more extensive in the rostral than in the caudal hippocampus. In the dentate gyrus, there was extensive loss of cells in the polymorphic layer (the hilar region) as well as patchy loss of granule cells. Although the subiculum was generally intact, there was some slight patchy loss of the most proximal portion of the field. The entorhinal cortex also demonstrated some cell loss. This was most noticeable in layers II and III, particularly deep in layer III. Finally, there was a substantial loss of cells in the medial septum. Other damage included infarcts in 


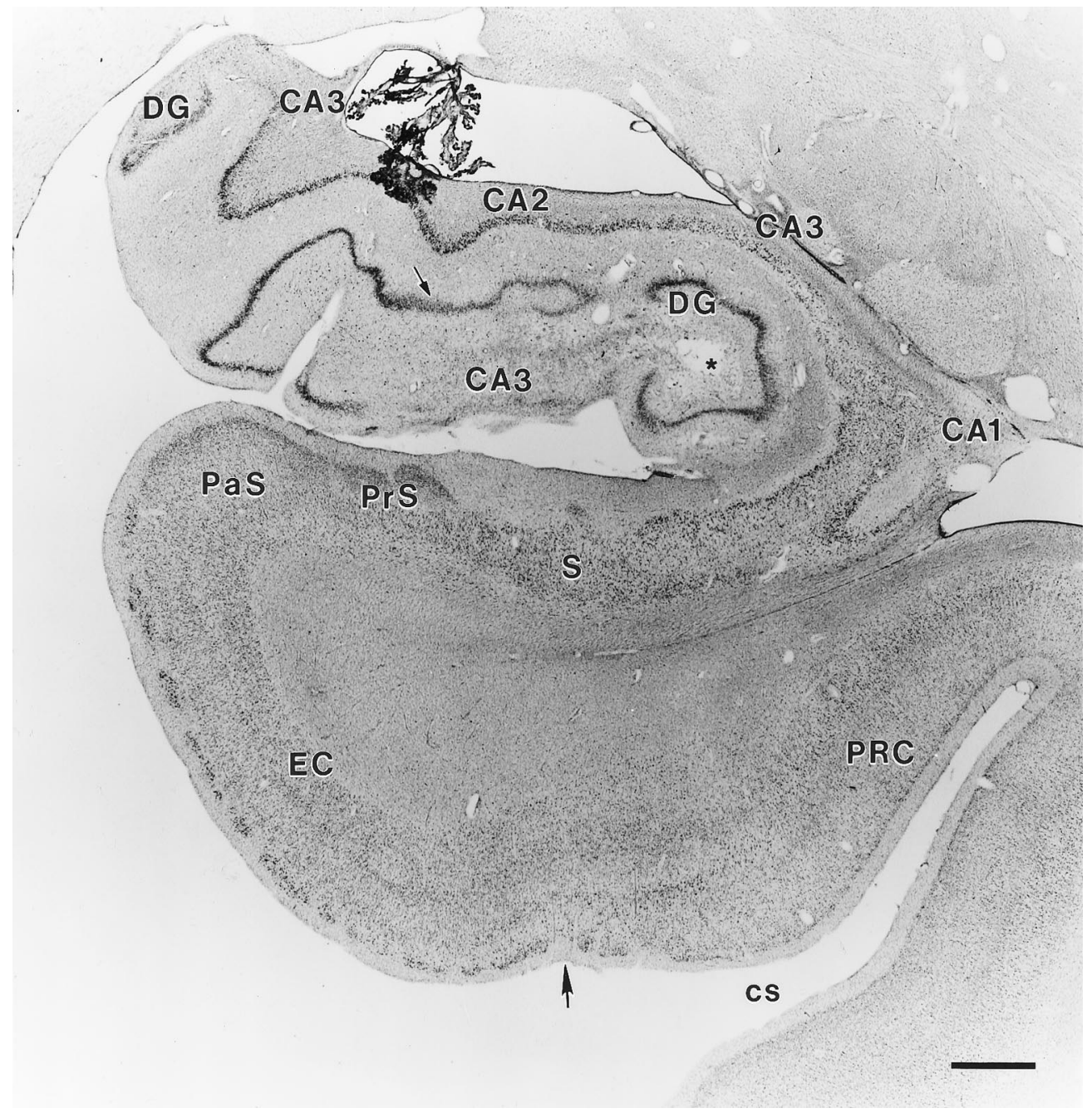

Figure 10. Coronal section through WH's right rostral hippocampal formation showing pronounced neuropathology. Extensive pyramidal cell loss is apparent in the CA1 and CA3 fields, and less substantial loss of CA2 pyramidal cells. The dentate gyrus appears very abnormal, with dispersion of the granule cell layer (small arrow) and complete loss of polymorphic cells. A star indicates a hole in the hilar region that is apparent at many rostrocaudal levels of the hippocampal formation; it does not appear to be histological artifact. Patchy cell loss is evident in the subiculum and the entorhinal cortex (layers III, V, and VI). A large arrow indicates the border between the entorhinal cortex and the perirhinal cortex. Abbreviations as in Figure 4. Scale bar, $1 \mathrm{~mm}$. the right lateral occipitotemporal cortex and the left medial temporal sulcus. In addition, small metastases were distributed in frontal, parietal, temporal, and occipital cortices, and in the basal ganglia.

Patient WH had the most distributed damage to the hippocampal formation of the three patients, including substantial cell loss in the CA fields, the dentate gyrus, and the subiculum, as well as cell loss in the entorhinal cortex. Unlike GD and LM, cell loss in WH's CA1 spared some of the superficial CA1 pyramidal cells. Also unlike in GD and LM, in WH the most extensive and complete loss of cells occurred in the CA3 field with partial damage to the CA2 and CA1 fields. As observed in LM, damage to the CA fields was more extensive in the rostral than in the caudal hippocampus. Furthermore, WH's dentate gyrus was very abnormal. Essentially complete loss of polymorphic cells was noted in addition to marked dispersion of the granule cell layer. The subiculum had extensive patchy cell loss, especially caudally. Holes and increased vascularization were present in the hippocampal region, particularly in the hilus. The entorhinal cortex of WH was also damaged, including bilateral cell loss in layers III, $\mathrm{V}$, and VI, and minimal loss in layer II. The cell loss in the subiculum and entorhinal cortex was worse on the left than on the right side. No damage was detected in perirhinal or parahippocampal cortices. WH's mammillary nuclei appeared small, gliotic, and had a higher cell density than normal. Other sites of damage in $\mathrm{WH}$ included an infarct in the pons and widespread perivascular enlargements in the white matter and striatum, particularly in the medial segment of the globus pallidus and the claustrum.

\section{Comparison of findings from MRI with postmortem findings}

Patients LM and WH had been evaluated with MRI in 1989, approximately 1 and 4 years before their deaths, respectively (Squire et al., 1990). MRIs for both patients showed decreased hippocampal volume with normal volumes for the parahippocampal gyrus and the temporal lobe, in agreement with postmortem findings (Figs. 9, 12). In addition, both the MRI and the postmortem analysis of WH revealed decreased mammillary nuclei volume and vascular dilation throughout the white matter of the brain. The fact that the information obtained from the MR images corresponds well with the postmortem findings underscores the usefulness of MRI procedures for estimating the extent of damage in amnesic patients. Nevertheless, the resolution of MRI is not sufficient to provide detailed information about the status of particular tissue, especially when there is cell loss without substantial volume change, e.g., the entorhinal cortex in patient $\mathrm{WH}$.

\section{DISCUSSION}

Neuropsychological and neuropathological findings from the three cases of amnesia reported here, patients GD, LM, and $\mathrm{WH}$, 

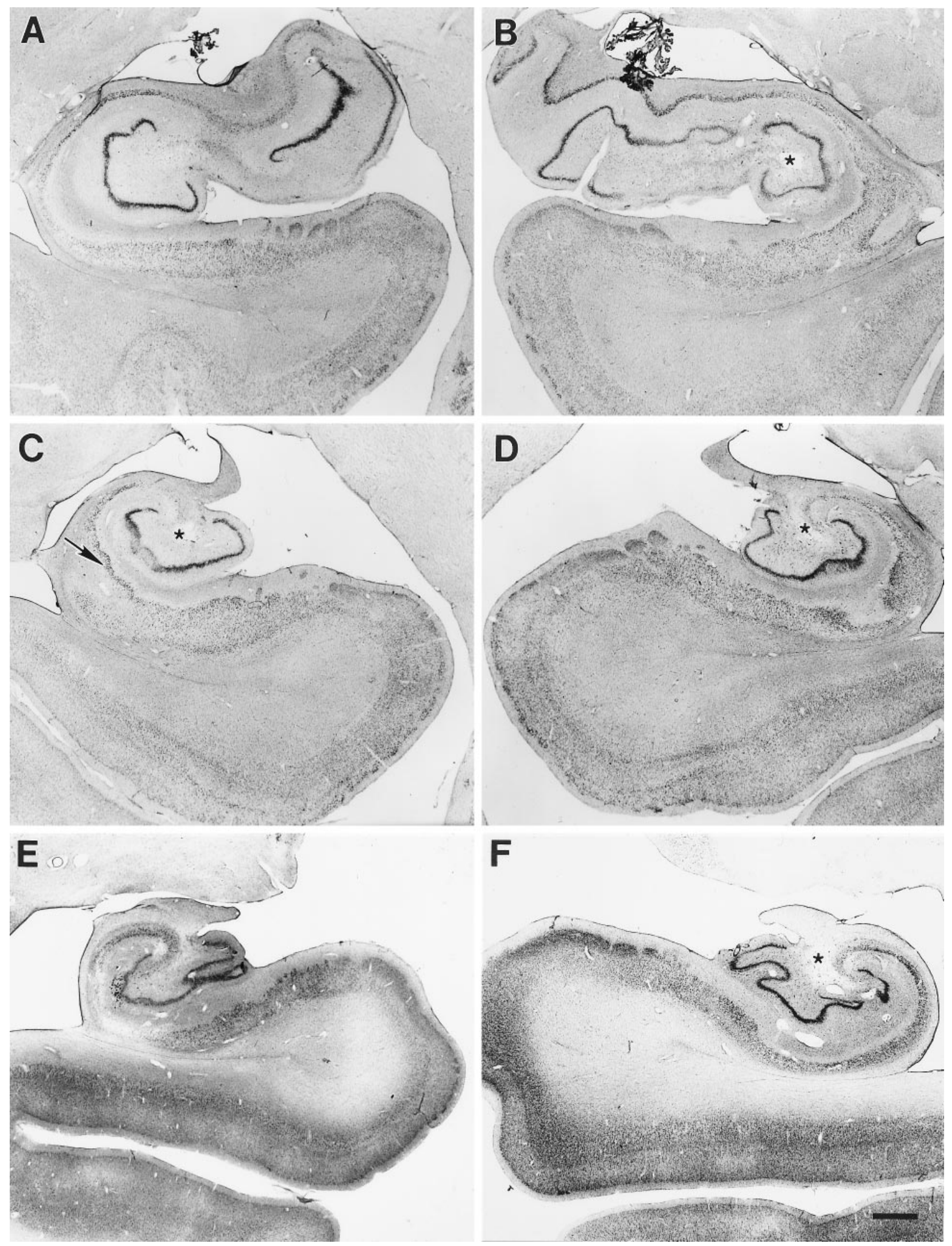

Figure 11. Coronal sections through the left and right sides of WH's hippocampal formation at rostral $(A, B)$, mid $(C, D)$, and caudal $(E, F)$ levels. In rostral hippocampus, more CA pyramidal cell loss is apparent on the left side $(A)$ than on the right $(B)$. Note the increased vascularization and the hole in the hilar region (indicated in each section on the right with a star). On the left side $(A)$, substantial loss of neurons is apparent in the subiculum and entorhinal cortex. In a midrostrocaudal level of the hippocampus, a hole is evident in the hilar region bilaterally (stars), and increased vascularization is evident on both sides $(C, D)$. In addition, damage is apparent in the hippocampal pyramidal cell fields and the dentate gyrus, including extensive pyramidal cell loss in the CA1 and CA3 fields, dispersion of the granule cell layer, and complete loss of polymorphic cells. Note the sparing of the superficial portion of the CA1 pyramidal cell layer on the left (arrow in $C$ ). Patchy cell loss is evident in layers III, V, and VI of the entorhinal cortex. The general pattern of damage continues through the caudal hippocampus, with increasing cell loss in the subiculum $(E, F)$. Some preservation of CA1 and CA2 pyramidal cells is visible on the right side $(F)$. Scale bar, $1 \mathrm{~mm}$. 

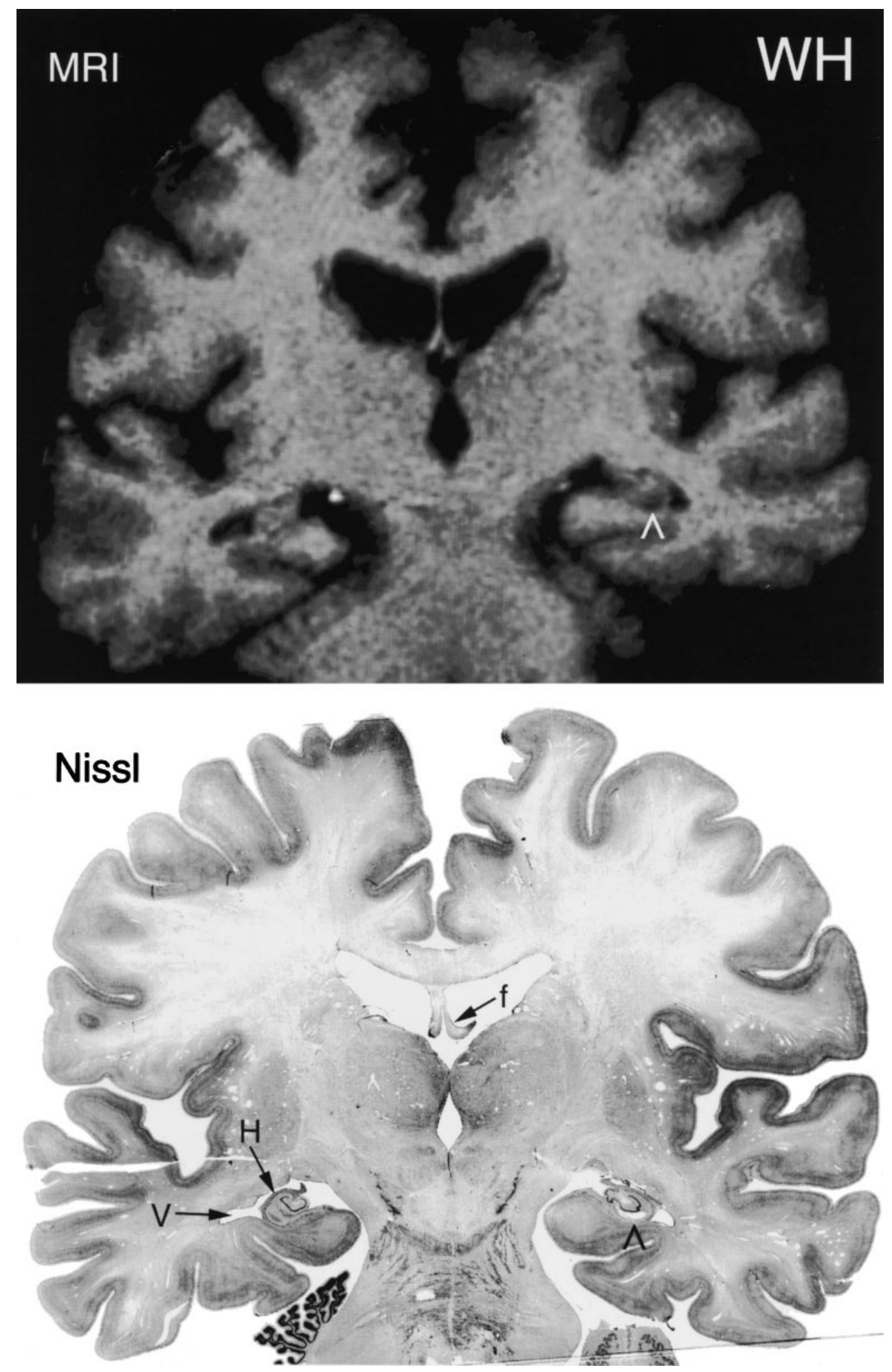

Figure 12. Comparison of a T1weighted MRI (top) and a Nissl-stained histological section (bottom) from the brain of patient $\mathrm{WH}$ at a level just rostral to the lateral geniculate nucleus. Note the enlarged ventricle $(V)$ adjacent to the hippocampus $(H)$. Note also the cystic defect in the right CA1 region of the hippocampus $(\wedge)$, which appears in the Nissl section and in the magnetic resonance image. The fornix $(f)$ is indicated in the Nissl-stained section. The right side of the brain is shown on the right side of the illustrations.

together with the previously reported findings from RB (ZolaMorgan et al., 1986), strongly support the idea that the hippocampal formation is important for memory. Furthermore, the extent of damage within the hippocampal formation appears to be related to the severity of memory impairment (Table 3). Patient $\mathrm{GD}$, like patient RB, had a bilateral lesion of the CA1 field of the hippocampus, moderately severe anterograde amnesia, and apparently little retrograde amnesia. Patient LM had more extensive damage to the hippocampal formation bilaterally that involved all the hippocampal CA cell fields, the dentate gyrus, and some cell loss in the entorhinal cortex. Like RB and GD, LM had moderately severe anterograde amnesia, but he had more severe and extensive retrograde amnesia covering at least 15 years. Patient WH had more distributed damage to the hippocampal formation than either GD or LM. His lesion involved bilaterally all the hippocampal cell fields, the dentate gyrus, the subiculum, and 

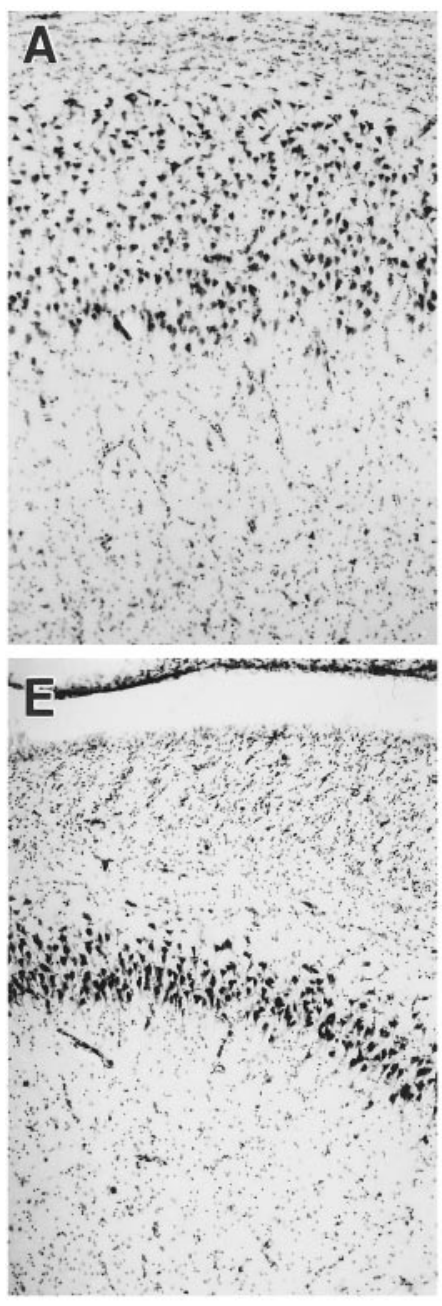

NORMAL
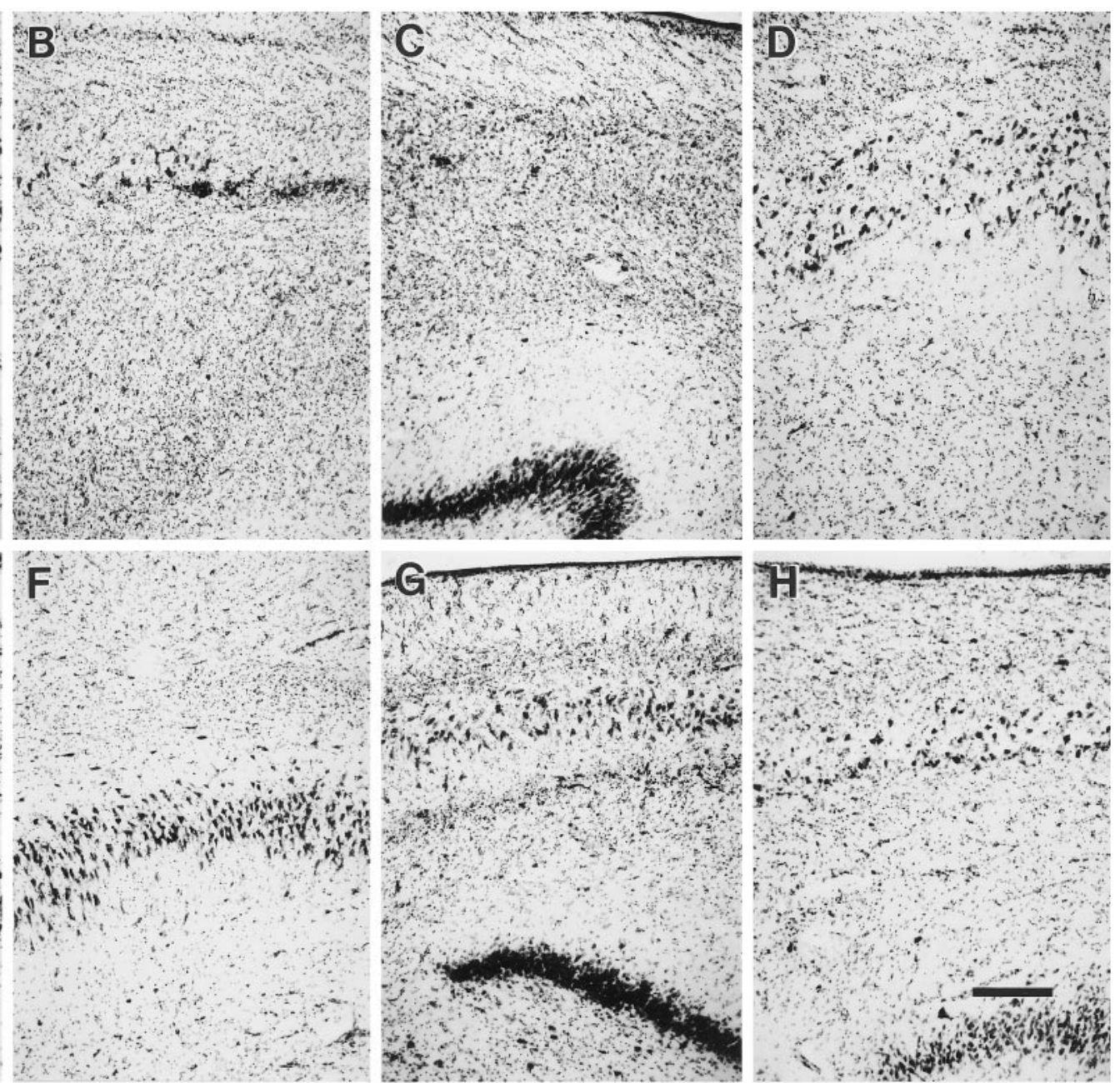

GD

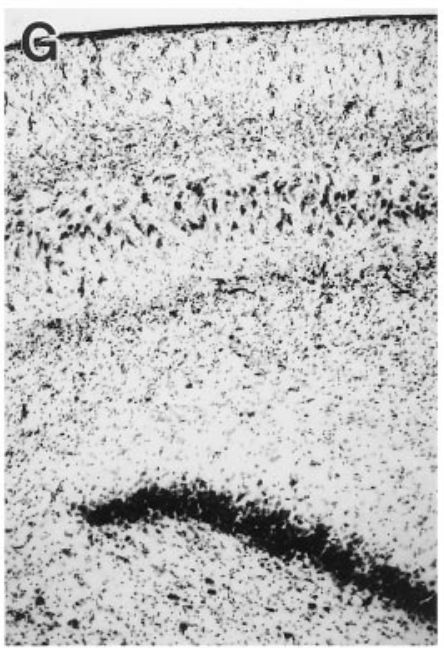

LM

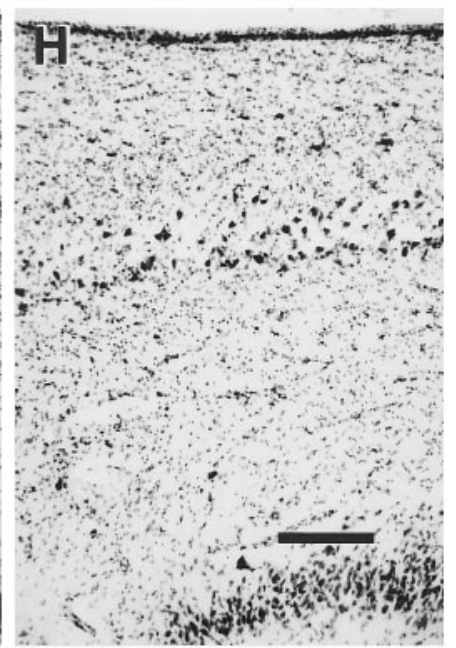

WH

Figure 13. Photomicrographs taken at a higher magnification of the CA1 field (top row) and the CA3 field (bottom row) of the hippocampal region of a normal brain $(A$ and $E)$, patient GD $(B$ and $F)$, patient LM $(C$ and $G)$, and patient WH $(D$ and $H)$. In the CA1 field, note the complete loss of CA1 pyramidal cells in GD $(B)$ and LM $(C)$, and patchy loss in WH $(D)$. In the CA3 field, no pyramidal cell loss is evident in GD $(F)$. However, there was extensive loss of CA3 pyramidal cells in $\mathrm{LM}(G)$ and in WH $(H)$. Scale bar, $0.5 \mathrm{~mm}$.

layers III, V, and VI of entorhinal cortex (slight cell loss was also apparent in layer II of entorhinal cortex). WH had more severe anterograde amnesia than the other patients, and he also had extensive, temporally graded retrograde amnesia involving as much as 25 years.

\section{The hippocampal formation and anterograde amnesia}

For the purpose of this discussion, we consider the hippocampal formation to consist of two components, i.e., the hippocampal region (including the dentate gyrus, the cell fields of the hippocampus proper, and the subicular complex) and the entorhinal cortex. The present findings, as summarized in Table 3, make two important points. First, the findings from patients RB, GD, and LM show that damage limited primarily to the hippocampal region, even when incomplete, is sufficient to produce a clinically significant memory impairment. (Of these three, only LM had damage outside the hippocampal region, involving some loss of cells in entorhinal cortex.) These findings correspond to previous findings in monkeys (Zola-Morgan et al., 1992; Alvarez et al., 1995) and rats (Mumby et al., 1992, 1995; Jaffard and Meunier,
1993; Jarrard, 1993). Taken together, the findings from all three species emphasize the important contribution to memory made by the hippocampal region (Squire, 1992). It was not possible to rank order with confidence the severity of anterograde memory impairment in RB, GD, and LM. However, the fact that GD had the least education, a low IQ, and was not always interested in testing, raises the possibility that his performance could have reflected in part these other factors, and that he was in fact less amnesic than the other patients.

The second point is that anterograde memory impairment can be exacerbated when more extensive damage occurs to the hippocampal formation. The damage in $\mathrm{WH}$, whose memory was the most severely impaired, involved the whole hippocampal formation, i.e., there was extensive cell loss in the hippocampal region (including the dentate gyrus, all the cell fields of the hippocampus, and the subicular complex), and there was additional cell loss in the entorhinal cortex. The same point can be made for the well studied amnesic patient, HM (Scoville and Milner, 1957), who exhibits more severe anterograde memory impairment than any of 


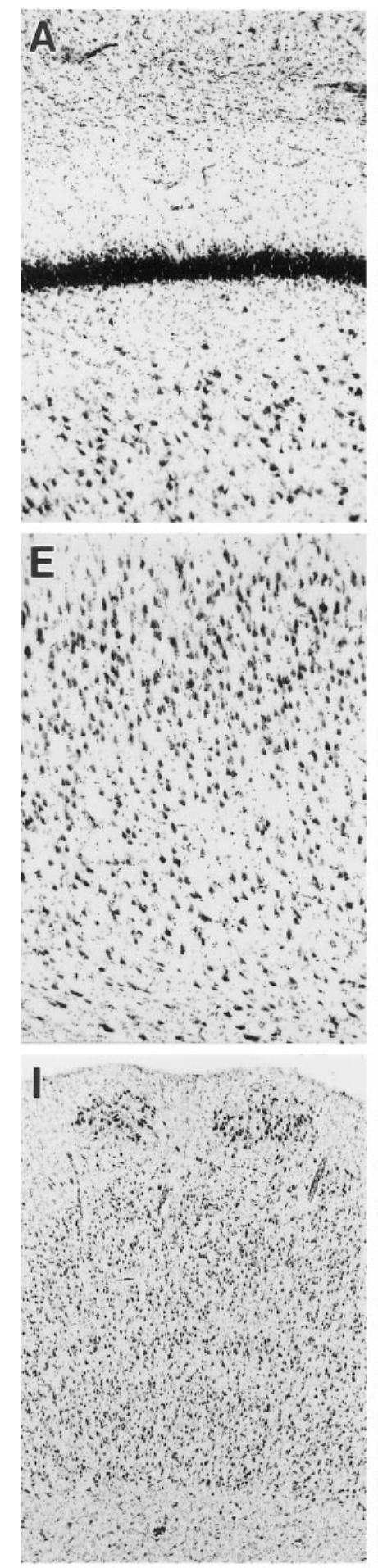

NORMAL
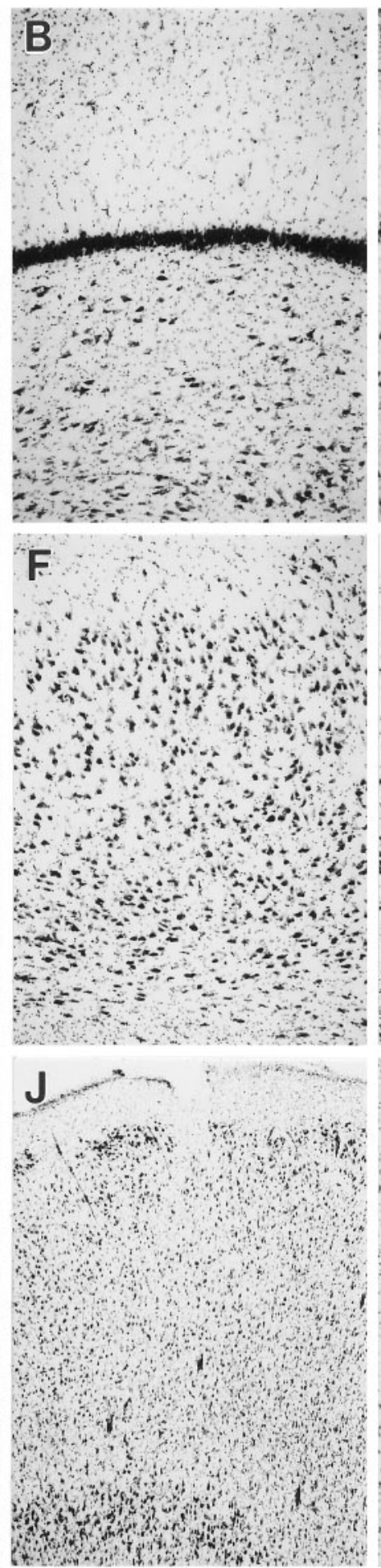

GD
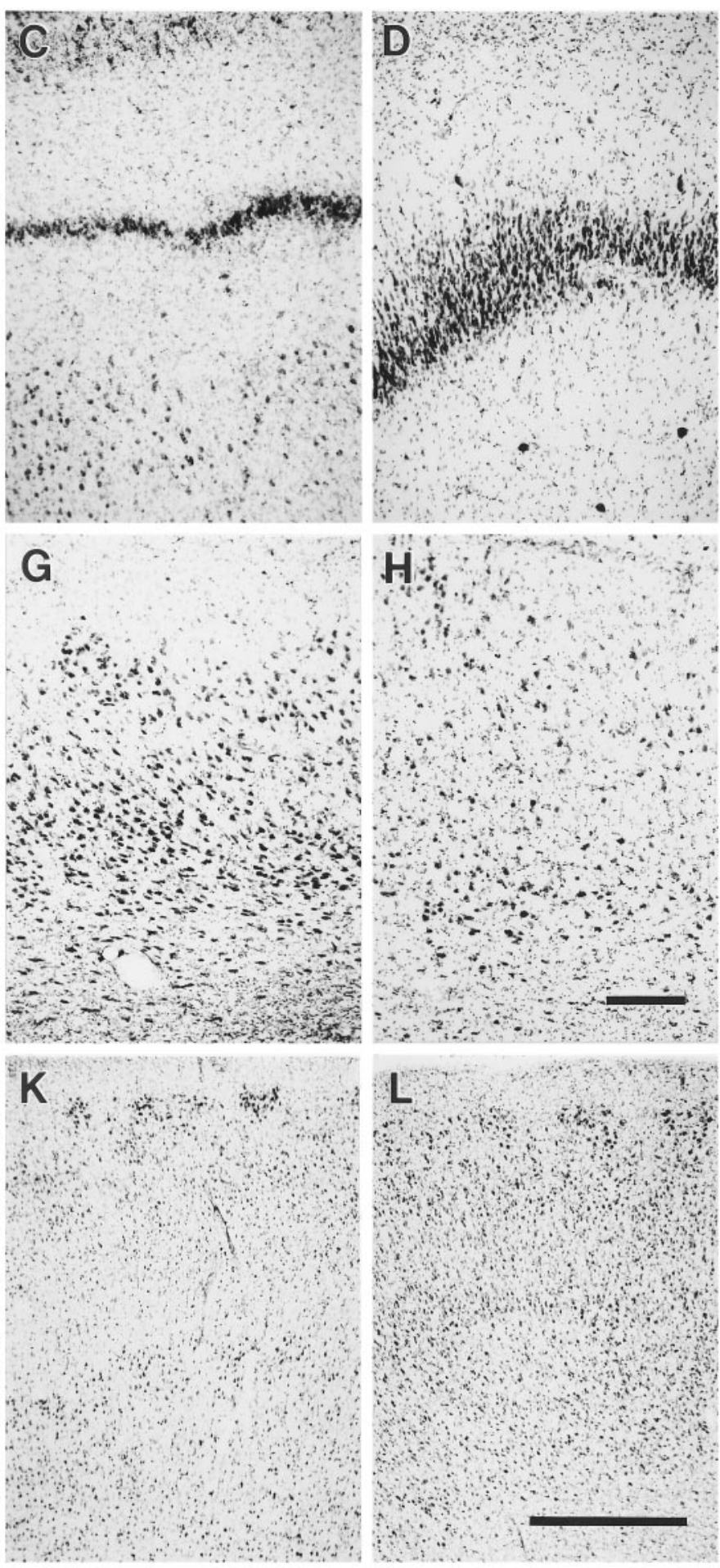

LM

WH

Figure 14. Photomicrographs taken at a higher magnification of the dentate gyrus $(A-D)$, subiculum $(E-H)$, and entorhinal cortex $(I-L)$ in, from left to right, a normal brain (NORMAL), GD, LM, and $W H$. In the dentate gyrus, granule polymorphic cell loss is visible in LM $(C)$. Dispersion of the granule cell layer is apparent in WH $(D)$. Patchy cell loss is evident in the subiculum in WH $(H)$. WH also had cell loss in the entorhinal cortex $(L)$. Scale bars, $0.5 \mathrm{~mm}$.

the patients described here. HM's radiological findings indicate that he has even more extensive damage to the hippocampal formation than WH (specifically in the entorhinal area), as well as damage to the adjacent perirhinal cortex (Corkin et al., 1996).
Work with monkeys has also shown that the severity of memory impairment increases with increasing damage to the medial temporal lobe (Zola-Morgan et al., 1994).

The work described here comes from patients with apparent 


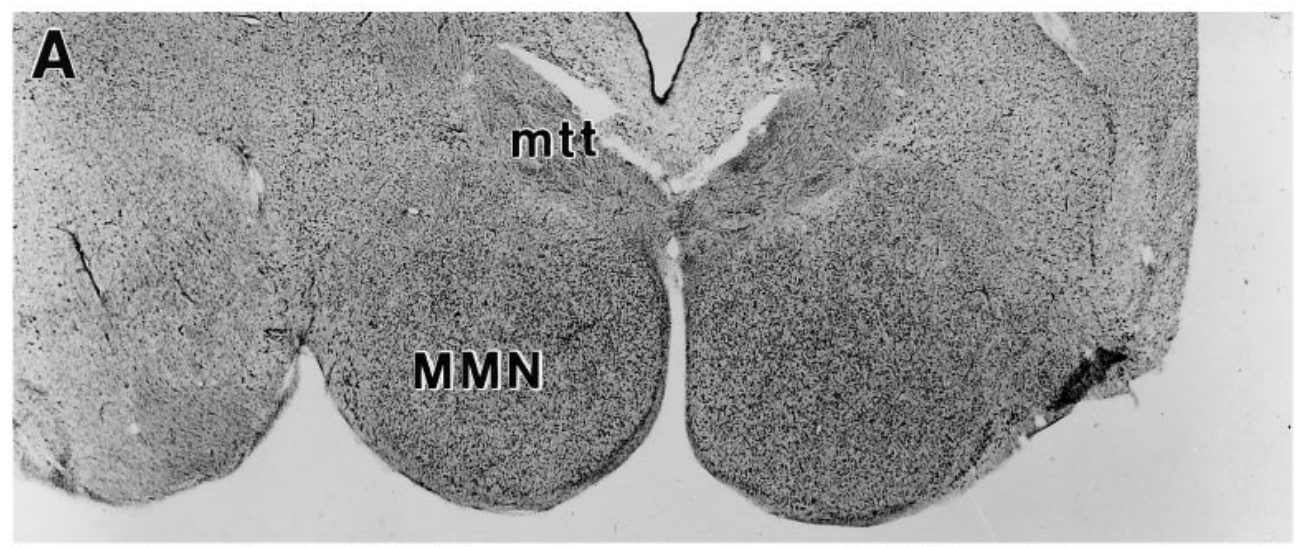

Figure 15. Photomicrographs of the medial mammillary nuclei in a normal brain $(A)$ and $\mathrm{WH}(B)$. WH's medial mammillary nuclei are small, gliotic, and more densely packed with cells $(B) . M M N$, Medial mammillary nuclei; $m t t$, mammillothalamic tract. Scale bar, $1 \mathrm{~mm}$.

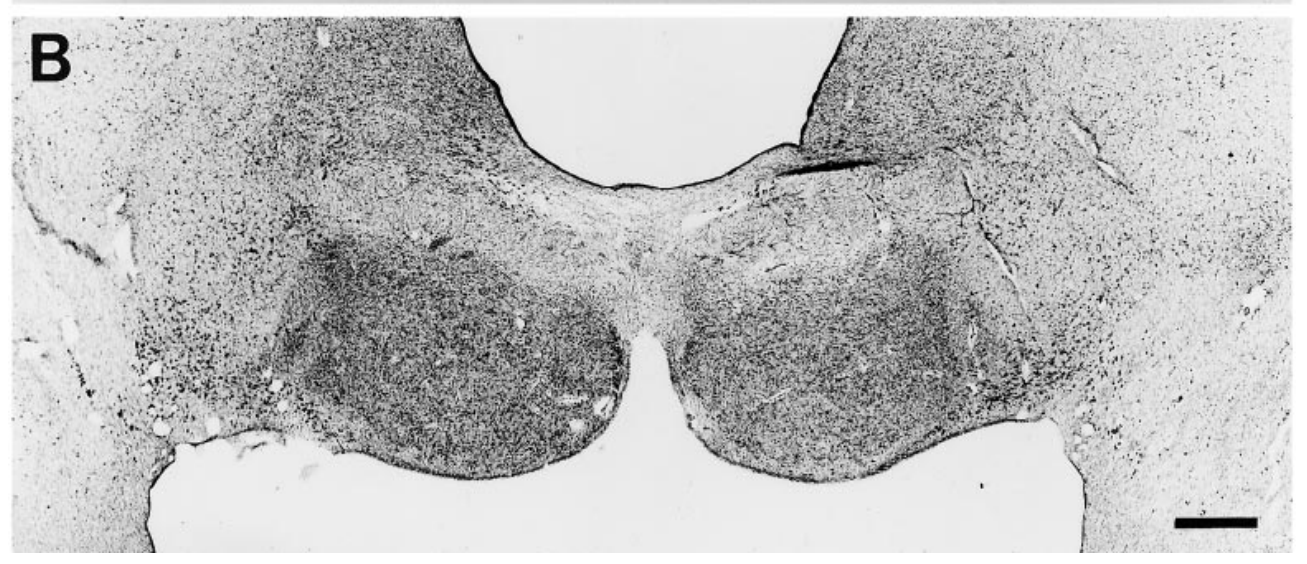

ischemic or anoxic damage to the hippocampal formation. The question naturally arises whether the cascade of events initiated by ischemia or anoxia might produce neuronal damage sufficient to impair behavioral performance, but not sufficient to progress to cell death and to be detectable in histopathology. This possibility has been referred to as covert damage (Bachevalier and Mishkin, 1989; Bachevalier and Meunier, 1996; Squire and Zola, 1996). It is an important issue, because if covert damage commonly occurs, then ischemic or anoxic lesions apparently limited to the hippocampal region cannot be taken as evidence that only the hippocampal region is dysfunctional. This issue has been addressed by the development of an animal model of cerebral ischemia in the monkey (Zola-Morgan et al., 1992). Monkeys with ischemia had detectable damage limited to the hippocampal region and exhibited about the same level of memory impairment as monkeys with known surgical lesions (made stereotaxically) that were limited to this same region (Zola-Morgan et al., 1992). Thus, the available data suggest that the severity of memory impairment in monkeys and humans with ischemic damage to the hippocampal region is about what would be predicted from the damage that can be detected histopathologically, and is comparable to the impairment that results from histopathologically similar neurosurgical lesions. This issue and other relevant experiments have been discussed in more detail elsewhere (Squire and Zola, 1996).

\section{The hippocampal formation and retrograde amnesia}

Damage limited primarily to the CA1 field of the hippocampal region (patients $\mathrm{RB}$ and GD) caused minimal retrograde amnesia, involving perhaps 1 or 2 years. Patient GD was previously thought to have extensive, temporally graded retrograde amnesia (MacKinnon and Squire, 1989; Squire et al., 1989). As described in Results, however, examination of all his test data together does not appear to provide strong or consistent support for a long temporal gradient, and GD's poor performance on some tests of retrograde amnesia are perhaps better attributed to his lower motivation and intellectual abilities (Table 1). More extensive damage, involving more of the hippocampal formation (patients LM and $\mathrm{WH}$ ), caused extensive, temporally graded retrograde amnesia. Memories acquired recently were more affected than memories acquired longer ago. In the case of LM, the impairment extended back at least 15 years, and in the case of WH, the impairment involved as much as 25 years (Beatty et al., 1987a; Salmon et al., 1988). To our knowledge, patients LM and WH are the first reported cases showing that extensive and temporally graded retrograde amnesia can occur after damage limited to the hippocampal formation. Specifically, temporally graded retrograde amnesia covering 15 years or more can occur after relatively circumscribed damage to the hippocampal formation. More extensive damage, involving additional temporal lobe structures, is not required to produce this deficit.

Early work on retrograde amnesia in amnesic patients, which depended primarily on anecdotal evidence of impaired memory, suggested that retrograde amnesia gradients are rather limited, perhaps a few years or less, even after substantial damage to the medial temporal lobe. One of the most influential early reports was that amnesic patient HM's retrograde amnesia covered only the 2 years preceding his medial temporal lobe surgery (Milner et al., 1968). HM's surgery occurred in 1953 when he was 27 years old (Scoville and Milner, 1957). The conclusion about his retrograde amnesia was based on the neurosurgeon's notes and on postoperative interviews with HM and his mother (Corkin, 1984). 
The report of HM's limited retrograde amnesia at the time was consistent with other reports of apparently brief retrograde amnesia after medial temporal lobe damage or removal. For example, Penfield and Milner (1958) had described two patients who developed amnesia after left unilateral temporal lobectomy. It was supposed that there was an undetected lesion of the hippocampus on the right side, and this was later confirmed in one of the two cases (case 2, below; Penfield and Mathieson, 1974). Case 1, a 28-year-old glove cutter (referred to as patient A), was reported as having retrograde amnesia " going back about 4 years." At followup, approximately 2.5 years after surgery, “... there is still a retrograde amnesia which, in the opinion of his family, covers the 4 years immediately preceding his operation." Patient A was additionally described as remembering clearly the events from more remote time periods and able to recall the names of his teachers and friends in his school days. Case 2 (referred to as patient B), a 41-year-old civil engineer, was reported to have retrograde amnesia that, according to his wife, covered approximately 2.5 months and eventually diminished to about 1 month. Finally, Victor et al. (1961) described a patient who in 1953 had a stroke that damaged the hippocampal formation bilaterally and caused significant anterograde amnesia. According to the patient's son, "... events which occurred before 1951 [2 years before the onset of amnesia] could be recalled with accuracy."

Some 20 years after the onset of his amnesia, patient HM was given formal tests to assess his memory for past public and personal events (Marslen-Wilson and Teuber, 1975; Corkin, 1984). The results of these tests suggested that he had retrograde amnesia covering up to 11 years before his surgery, i.e., more extensive retrograde amnesia than was first supposed. We suggest that patients who are interpreted as having retrograde amnesia limited to a few years, based on clinical interviews or family reports, often will turn out to have much more extensive retrograde amnesia when formal tests are given. Note, for example, that after formal testing the estimate of HM's retrograde amnesia increased from 2 to 11 years (Corkin, 1984).

We also note that HM's ability to recall the names of famous tunes was below the normal range for the 1930s as well as the 1940s (Corkin, 1984). Thus, it is possible that HM's remote memory impairment might be even more extensive than the 11 year estimate. We also note that HM became amnesic at a much younger age (27 years old) than the amnesic patients reported here and elsewhere (Squire et al., 1989). Eleven years before his surgery, HM would have been only 16 years old, and memory for public events cannot be reliably probed from any earlier time periods. Specifically, normal subjects aged 16 and 17 do very poorly on public events questions involving the immediately preceding decade (Squire, 1974). We suggest that if HM had become amnesic after the age of 40, and if testing were done soon thereafter (not 20 years later), such testing might have revealed very extensive, temporally graded retrograde amnesia.

Recent prospective studies in experimental animals have substantiated the idea that medial temporal lobe damage can produce temporally graded retrograde amnesia (Winocur, 1990; ZolaMorgan and Squire, 1990; Kim and Fanselow, 1992; Cho et al., 1993; Kim et al., 1995). In each case, remote memories were retained better than recent memories, just as in human amnesia. The extent of the retrograde amnesia varied from a few days to a few months. Several factors may determine the extent of retrograde amnesia, including species, task, the locus and extent of the lesion, and especially the time course over which the material being tested is forgotten by normal subjects. Note that the studies of experimental animals, which yielded retrograde amnesia gradients covering days to months, have involved information that is normally forgotten across days, weeks, and months. In contrast, the studies of human amnesia, demonstrating extensive, temporally graded retrograde amnesia, have involved information such as famous faces, famous public events, and salient personal memories that are forgotten only gradually across many decades. Note also that the single example in which testing revealed a less extensive temporally graded retrograde amnesia in humans (i.e., less than 10 years) comes from tests involving former one-season television programs (Squire et al., 1975), where most of the forgetting occurs within a decade (Squire, 1989).

Findings of extensive, temporally graded retrograde amnesia led to the idea that, as the years pass after learning, there is gradual reorganization or consolidation within long-term memory storage. The importance of structures in the medial temporal lobe gradually diminishes and more permanent memory storage develops (presumably in neocortex) that is independent of this region (for a recent review, see Squire and Alvarez, 1995). What kind of process could exhibit such a long time course? As discussed elsewhere (Alvarez and Squire, 1994; Squire and Alvarez, 1995), one candidate for gradual, long-term reorganization of memory is morphological growth and change within the cortical areas thought to participate in long-term information storage. Note that the normal process of forgetting occurs over a similarly long time course. Note, too, that the available facts do not require the idea that memories are first stored in the hippocampal formation and then move to neocortex. The data require only that the hippocampal formation is essential temporarily for long-term memory. As time passes, the neocortex becomes able to support long-term memory independently of the hippocampal formation. Events that occur during the interval after learning, perhaps including endogenous activity within the hippocampal formation, may drive consolidation in neocortex.

\section{REFERENCES}

Alexander MP, Freedman M (1984) Amnesia after anterior communicating aneurysm rupture. Neurology 34:752-757.

Alvarez P, Squire LR (1994) Memory consolidation and the medial temporal lobe: a simple network model. Proc Natl Acad Sci USA 91:7041-7045.

Alvarez P, Zola-Morgan S, Squire LR (1995) Damage limited to the hippocampal region produces long-lasting memory impairment in monkeys. J Neurosci 15:3796-3807.

Amaral DG, Insausti R (1990) The hippocampal formation. In: The human nervous system (Paxinos G, ed). New York: Academic.

Bachevalier J, Meunier M (1996) Cerebral ischemia: are the memory deficits associated with hippocampal cell loss? Hippocampus, in press.

Bachevalier J, Mishkin M (1989) Mnemonic and neuropathological effects of occluding the posterior cerebral artery in Macaca mulatta. Neuropsychologia 27:83-105.

Beatty WW, Salmon DP, Bernstein N, Butters N (1987a) Remote memory in a patient with amnesia due to hypoxia. Psychol Med 17:657-665.

Beatty WW, Salmon DP, Bernstein N, Martone M, Lyon L, Butters N (1987b) Procedural learning in a patient with amnesia due to hypoxia. Brain Cogn 6:386-402.

Benton AL, Hamsher KD (1976) Multilingual aphasia examination. Iowa City: University of Iowa.

Benzing WC, Squire LR (1989) Preserved leaning and memory in amnesia: intact adaptation-level effects and learning of stereoscopic depth. Behav Neurosci 103:538-547.

Braffman BH, Zimmerman RA, Trojanowski JQ, Gonatas NK, Hickey WF, Schaepfer WW (1988) Brain MR: pathologic correlation with gross and histopathology. 1. Lacunar infarction and Virchow-Robin spaces. AJR Am J Roentgenol 151:551-558.

Brierley JB, Graham DI (1984) Hypoxia and vascular disorders of the central nervous system. In: Greenfield's neuropathology, 4th Ed (Adams JH, Corsellis JAN, Duchen LW, eds), pp 125-207. London: Arnold. 
Cave CB, Squire LR (1992) Intact and long-lasting repetition priming in amnesia. J Exp Psychol Learn Mem Cogn 18:509-520.

Cho YH, Beracochea D, Jaffard R (1993) Extended temporal gradient for retrograde and anterograde amnesia produced by ibotenic entorhinal cortex lesions in mice. J Neurosci 13:1759-1766.

Cole FM, Yates PO (1968) Comparative incidence of cerebrovascular lesions in normotensive and hypertensive patients. Neurology 18:255-259.

Corkin S (1984) Lasting consequences of bilateral medial temporal lobectomy: clinical course and experimental findings in H.M. Semin Neurol 4:249-259.

Corkin S, Amaral DG, Johnson KA, Hyman BT (1996) HM's MRI scan shows sparing of the posterior half of the hippocampus and parahippocampal gyrus. J Neurosci, in press.

Crovitz HF, Schiffman H (1974) Frequency of episodic memories as a function of their age. Bull Psychon Soc 4:517-518.

Cummings JL, Tomiyasu S, Read S, Benson DF (1984) Amnesia with hippocampal lesions after cardiopulmonary arrest. Neurology 34:679-681.

Damasio AR, Graff-Radford NR, Eslinger PJ, Damasio H, Kassell N (1985) Amnesia following basal forebrain lesions. Arch Neurol 42:263-271.

DeJong RN, Itabashi HH, Olson JR (1968) "Pure" memory loss with hippocampal lesions: a case report. Trans Am Neurol Assoc 93:31-34.

Delattre JY, Krol G, Thaler HT, Posner JB (1988) Distribution of brain metastases. Arch Neurol 45:741-744.

Duyckaerts C, Derouesne C, Signoret JL, Gray F, Escourolle R, Castaigne P (1985) Bilateral and limited amygdalohippocampal lesions causing a pure amnesic syndrome. Ann Neurol 18:314-319.

Garcia JH, Conger KA (1981) Ischemic brain injuries: structural and biochemical effects. In: Brain failure and resuscitation (Grenvika A, Safar P, eds), pp 35-54. New York: Churchill Livingstone.

Glees P, Griffith HB (1952) Bilateral destruction of the hippocampus (cornu ammonis) in a case of dementia. Psychiatr Neurol Med Psychol 123:193-204.

Goodglass H, Kaplan E (1972) The assessment of aphasia and related disorders. Philadelphia: Lea and Febiger.

Graff-Radford NR, Tranel D, Van Hoesen GW, Brandt J (1990) Diencephalic amnesia. Brain 113:1-25.

Grunthal E (1947) Über das klinische bild nach umschriebenem beiderseitigem ausfall der ammonshornrinde. Monatsschr Psychiatr Neurol 113:1-16.

Heaton RK (1981) Wisconsin card sorting test manual. Odessa, FL: Psychology Assessment Resources.

Hirsch FR, Paulson OB, Hansen HH, Vraa-Jensen J (1982) Intracranial metastases in small cell carcinoma of the lung: correlation of clinical and autopsy findings. Cancer 50:2433-2437.

Houser CR, Miyashiro JE, Schwartz BE, Walsh GO, Rich JR, DelgadoEscueta AV (1990) Altered patterns of dynorphin immunoreactivity suggests mossy fiber reorganization in human hippocampal epilepsy. J Neurosci 10:267-282.

Hutchins B, Weber JT (1983) A rapid myelin stain for frozen sections: modification of the Heidenhain procedure. J Neurosci Methods 7:289-294.

Insausti R, Amaral DG, Cowan WM (1987) The entorhinal cortex of the monkey. II. Cortical afferents. J Comp Neurol 264:356-395.

Insausti R, Tunon T, Sobreviela T, Insausti AM, Gonzalo LM (1995) The human entorhinal cortex: a cytoarchitectonic analysis. J Comp Neurol 355:171-198.

Jaffard R, Meunier M (1993) Role of the hippocampal formation in learning and memory. Hippocampus 3:203-218.

Janowsky JS, Shimamura AP, Kritchevsky M, Squire LR (1989) Cognitive impairment following frontal lobe damage and its relevance to human amnesia. Behav Neurosci 3:548-560.

Jarrard LE (1993) On the role of the hippocampus in learning and memory in the rat. Behav Neural Biol 60:9-26.

Kaplan EF, Goodglass H, Weintraub S (1983) The Boston naming test. Philadelphia: Lea and Febiger.

Kim JJ, Fanselow MS (1992) Modality-specific retrograde amnesia of fear. Science 256:675-677.

Kim JJ, Clark RE, Thompson RF (1995) Hippocampectomy impairs the memory of recently, but not remotely, acquired trace eyeblink conditioned responses. Behav Neurosci 109:195-203.

Knowlton BJ, Squire LR (1994) The information acquired during artificial grammar learning. J Exp Psychol Learn Mem Cogn 20:79-91.
Knowlton BJ, Ramus SJ, Squire LR (1992) Intact artificial grammar learning in amnesia: dissociation of classification learning and explicit memory for specific instances. Psychol Sci 3:172-179.

Knowlton BJ, Squire LR, Gluck M (1994) Probabilistic classification learning in amnesia. Learn Memory 1:106-120.

Kritchevsky M, Squire LR (1993) Permanent global amnesia with unknown etiology. Neurology 43:326-332. Lorente de Nó R (1934) Studies on the structure of the cerebral cortex. II. Continuation of the study of the ammonic system. J Psychol Neurol 46:113-177.

Lorente de Nó R (1934) Studies on the structure of the cerebral cortex. II. Continuation of the study of the ammonic system. J Psychol Neruol 46:113-177.

MacKinnon DF, Squire LR (1989) Autobiographical memory and amnesia. Psychobiology 17:247-256.

Markowitsch HJ (1988) Diencephalic amnesia: a reorientation towards tracts? Brain Res Rev 13:351-370.

Marslen-Wilson WD, Teuber HL (1975) Memory for remote events in anterograde amnesia: recognition of public figures from news photographs. Neuropsychologia 13:353-364.

Mattis S (1976) Dementia rating scale. In: Geriatric psychiatry, Vol 1 (Bellack R, Karasu B, eds), pp 77-121. New York: Grune and Stratton.

Mayes AR (1988) Human organic memory disorders. New York: Oxford UP.

McCormick PD (1979) Autobiographical memory in the aged. Can J Psychol 33:118-124.

Milner B, Corkin S, Teuber HL (1968) Further analysis of the hippocampal amnesic syndrome: 14-year follow-up of H.M. Neuropsychologia 6:215-234.

Morris MK, Bowers D, Chatterjee A, Heilman KM (1992) Amnesia following a discrete basal forebrain lesion. Brain 115:1827-1847.

Mumby DG, Pinel JPJ, Kornecook TJ (1992) Dissociating the effects of hippocampal and amygdalar lesions in rats with a battery of nonspatial memory tasks. Soc Neurosci Abstr 18:1423.

Mumby DG, Pinel JPJ, Kornecook TJ, Shen MJ, Redila VA (1995) Memory deficits following lesions of hippocampus or amygdala: assessment by an object-memory test battery. Psychobiology 23:26-36.

Muramoto O, Kuru H, Sugishita M, Toyokura Y (1979) Pure memory loss with hippocampal lesions: a pneumoencephalographic study. Arch Neurol 36:54-56.

Musen G, Squire LR (1991) Normal acquisition of novel verbal information in amnesia. J Exp Psychol Learn Mem Cogn 17:1095-1104.

Musen G, Squire LR (1992) Nonverbal priming in amnesia. Mem Cognit 20:441-448.

Musen G, Squire LR (1993) On the implicit learning of novel associations by amnesic patients and normal subjects. Neuropsychology 7:119-135.

Musen G, Shimamura AP, Squire LR (1990) Intact test-specific reading skill in amnesia. J Exp Psychol Learn Mem Cogn 6:1068-1076.

Osterrieth PA (1944) Le test de copie d'une figure complexe [The test of copying a complex figure]. Arch Psychol 30:306-356.

Penfield W, Mathieson G (1974) Memory: autopsy findings and comments on the role of hippocampus in experiential recall. Arch Neurol 31:145-154.

Penfield W, Milner B (1958) Memory deficit produced by bilateral lesions in the hippocampal zone. Arch Neurol Psychiatry 79:475-497.

Phillips S, Sangalang V, Sterns G (1987) Basal forebrain infarction: a clinicopathologic correlation. Arch Neurol 44:1134-1138.

Plum F (1983) What causes infarction in ischemic brain? The Robert Wartenberg Lecture. Neurology 33:222-233.

Polich J, Squire LR (1993) P300 from amnesic patients with bilateral hippocampal lesions. Electroencephalogr Clin Neurophysiol 86:408-417.

Ramon y Cajal S (1901-1902) Estudios sobre la corteza cerebral humana. Trab Inst Cajal Invest Biol 1:1-227.

Rey A (1964) L'examinen clinique en psychologie [The clinical exam in psychology]. Paris: Universitaires de France.

Rose A (1927) Die sog. Riechrinde beim menschen und beim affen. II. Teil des "allocortex bei tier und mensch." J Psychol Neurol 34:261-401.

Salmon DP, Lasker BR, Butters N, Beatty WW (1988) Remote memory in a patient with circumscribed amnesia. Brain Cogn 7:201-211.

Scoville WB, Milner B (1957) Loss of recent memory after bilateral hippocampal lesions. J Neurol Neurosurg Psychiatry 20:11-21.

Shimamura AP, Squire LR (1986) Memory and metamemory: a study of the feeling-of-knowing phenomenon in amnesic patients. J Exp Psychol Learn Mem Cogn 12:452-460. 
Shimamura AP, Squire LR (1989) Impaired priming of new associations in amnesia. J Exp Psychol Learn Mem Cogn 15:721-728.

Squire LR (1974) Remote memory as affected by aging. Neuropsychologia $12: 429-435$.

Squire LR (1989) On the course of forgetting in very long-term memory. J Exp Psychol Learn Mem Cogn 15:241-245.

Squire LR (1992) Memory and the hippocampus: a synthesis from findings with rats, monkeys, and humans. Psychol Rev 99:195-231.

Squire LR, Alvarez P (1995) Retrograde amnesia and memory consolidation: a neurobiological perspective. Curr Opin Neurobiol 5:169-177.

Squire LR, Frambach M (1990) Cognitive skill learning in amnesia. Psychobiology 18:109-117.

Squire LR, Zola SM (1996) Ischemic brain damage and memory impairment: a commentary. Hippocampus, in press.

Squire LR, Slater PC, Chace PM (1975) Retrograde amnesia: temporal gradient in very long-term memory following electroconvulsive therapy. Science 187:77-79.

Squire LR, Shimamura AP, Graf P (1987) Strength and duration of priming effects in normal subjects and amnesic patients. Neuropsychologia 25:195-210.

Squire LR, Haist F, Shimamura AP (1989) The neurology of memory: quantitative assessment of retrograde amnesia in two groups of amnesic patients. J Neurosci 9:828-839.

Squire LR, Amaral DG, Press GA (1990) Magnetic resonance measurements of hippocampal formation amd mammillary nuclei distinguish medial temporal lobe and diencephalic amnesia. J Neurosci 10:3106-3117.

Suzuki F, Junier MP, Guilhem D, Sorensen JC Neurol, (1995) Morphogenic effect of kainate on adult hippocampal neurons associated with a prolonged expression of brain-derived neurotrophic factor. Neuroscience 64:665-674.

Tomlinson BE, Blessed G, Roth M (1968) Observations on the brains of non-demented old people. J Neurol Sci 7:331-356.

Tomlinson BE, Blessed G, Roth M (1970) Observations on the brains of demented old people. J Neurol Sci 11:205-242.

Van Buren JM, Borke RC (1972) The mesial temporal substratum of memory: anatomical studies in three individuals. Brain 95:599-632.
Victor M, Agamanolis D (1990) Amnesia due to lesions confined to the hippocampus: a clinical-pathologic study. J Cognit Neurosci 2:246-257.

Victor M, Angevine JB, Mancall EL, Fisher CM (1961) Memory loss with lesions of hippocampal formation. Arch Neurol 5:244.

Victor M, Adams RD, Collins GH (1989) The Wernicke-Korsakoff syndrome and related neurological disorders due to alcoholism and malnutrition, 2nd Ed. Philadelphia: Davis.

von Bechterew W (1900) Demonstration eines gehirns mit zerstörung der vorderen und inneren theile der hirnrinde beider schlafenlappen. Neurologisches Zentralb 19:990-991.

Warrington EK (1984) Recognition memory test. Windsor: NFERNelson.

Warrington EK, Duchen LW (1992) A re-appraisal of a case of persistent global amnesia following right temporal lobectomy: a clinicopathological study. Neuropsychologia 30:437-450.

Winocur G (1990) Anterograde and retrograde amnesia in rats with dorsal hippocampal or dorsomedial thalamic lesions. Behav Brain Res 38:145-154.

Woods BT, Schoene W, Kneisley L (1982) Are hippocampal lesions sufficient to cause lasting amnesia? J Neurol Neurosurg Psychiatry 45:243-247.

Zola-Morgan S, Squire LR (1990) The primate hippocampal formation: evidence for a time-limited role in memory storage. Science 250:288-290.

Zola-Morgan S, Squire LR (1993) Neuroanatomy of memory. Annu Rev Neurosci 16:547-563.

Zola-Morgan S, Squire LR, Amaral DG (1986) Human amnesia and the medial temporal region: enduring memory impairment following a bilateral lesion limited to field CA1 of the hippocampus. J Neurosci 6:2950-2967.

Zola-Morgan S, Squire LR, Rempel NL, Clower RP, Amaral DG (1992) Enduring memory impairment in monkeys after ischemic damage to the hippocampus. J Neurosci 11:4355-4370.

Zola-Morgan S, Squire LR, Ramus SJ (1994) Severity of memory impairment in monkeys as a function of locus and extent of damage within the medial temporal lobe memory system. Hippocampus 4:1-13. 